\title{
Tailoring Blue-Green Double Emissions in Carbon Quantum Dots via Co-Doping Engineering by Competition Mechanism between Chlorine-Related States and Conjugated $\pi$-Domains
}

\author{
Xue Sun ${ }^{1,2}$, Huilian Liu ${ }^{1,2, *}$, Lili Yang ${ }^{1,2, *}$, Xinying Wang ${ }^{3}$, Weiqiang Yang ${ }^{4}$, Maobin Wei ${ }^{1,2}$, \\ Xiaoyan Liu ${ }^{1,2}$, Jian Cao ${ }^{1,2}$, Jinghai Yang ${ }^{1,2}$ and Scott Guozhong Xing ${ }^{5, *}$ \\ 1 Key Laboratory of Functional Materials Physics and Chemistry of the Ministry of Education, \\ Jilin Normal University, Changchun 130013, China; xuesun1992@126.com (X.S.); jlsdzccw@126.com (M.W.); \\ liuxiaoyan1437@163.com (X.L.); caojian_928@163.com (J.C.); jhyang1@jlnu.edu.cn (J.Y.) \\ 2 National Demonstration Center for Experimental Physics Education, Jilin Normal University, \\ Siping 136000, China \\ 3 School of Engineering and Architecture, Northeast Electric Power University, Jilin 132012, China; \\ wangxinying.2008@163.com \\ 4 Centre for Advanced Optoelectronic Functional Materials Research and Key Laboratory of UV-Emitting \\ Materials and Technology (Northeast Normal University), Ministry of Education, Changchun 130024, China; \\ yangweiqiang123456@163.com \\ 5 United Microelect Corp. Ltd., 3 Pasir Ris Dr 12, Singapore 519528, Singapore \\ * Correspondence: lh1541@126.com or liuhuilian@jlnu.edu.cn (H.L.); llyang1980@126.com or \\ llyang@jlnu.edu.cn (L.Y.); scott_xing@umc.com or guozhongupenn@gmail.com (S.G.X.); \\ Tel./Fax: +86-434-3294566 (L.Y.); Tel./Fax: +65-66449594 (S.G.X.)
}

Received: 22 June 2018; Accepted: 17 August 2018; Published: 21 August 2018

\begin{abstract}
Representing single-layer to tens of layers of graphene in a size less than $30 \mathrm{~nm}$, carbon quantum dots (CQDs) is becoming an advanced multifunctional material for its unique optical, electronic, spin and photoelectric properties induced by the quantum confinement effect and edge effect. In present work, upon co-doping engineering, nitrogen and chlorine co-doped CQDs with uniquely strong blue-green double emissions are developed via a facile and one-pot hydrothermal method. The crystalline and optical properties of CQDs have been well manipulated by tuning the mole ratio of nitrogen/chlorine and the reaction time. The characteristic green emission centered at $512 \mathrm{~nm}$ has been verified, originating from the chlorine-related states, the other blue emissions centered at $460 \mathrm{~nm}$ are attributed to the conjugated $\pi$-domain. Increasing the proportion of 1,2,4-benzentriamine dihydrochloride can effectively adjust the bandgap of CQDs, mainly caused by the synergy and competition of chlorine-related states and the conjugated $\pi$-domain. Prolonging the reaction time promotes more nitrogen and chlorine dopants incorporate into CQDs, which inhibits the growth of CQDs to reduce the average size of CQDs down to $1.5 \mathrm{~nm}$, so that the quantum confinement effect dominates into play. This work not only provides a candidate with excellent optical properties for heteroatoms-doped carbon materials but also benefits to stimulate the intensive studies for co-doped carbon with chlorine as one of new dopants paradigm.
\end{abstract}

Keywords: carbon quantum dots; co-doping; competition mechanism; conjugated $\pi$-domain

\section{Introduction}

Nanocrystals have received both fundamental and practical attention owing to their potential applications in many fields such as ultrasensitive biosensing, imaging agents, photothermal therapy 
and catalysts, due to their tunable optical properties and high catalytic activities [1-9]. Carbon quantum dots (CQDs) are regarded as an emerging functional materials due to their great advantages such as biocompatibility, low toxicity, simple preparation technique and high photostability [10-18], which have been widely applied in the fields of optical detection probes, light-emitting diode, photocatalysis and so on [15-17]. Doping heteroatom into CQDs is an effective technique to endow new or improved photoluminescence properties and extend their application potential.

So far, the elements such as S, N, B, Na, Se and $\mathrm{Cl}$ have been served as dopant in CQDs to exhibit distinct photoluminescence properties and the corresponding origination of emission has been discussed in detail [17-20]. For instance, Yang et al. demonstrate that $\mathrm{N}$ and Se doping can achieve a tunable emission wavelength in CQDs and the fluorescence is close to the surface activity groups [21]; Qu et al. prepared S, N co-doped CQDs with multicolor emissions and found that the luminescence may come from the carbon core [18]. Obviously, the above works not only realized the tunable emission in CQDs via heteroatom doping but proposed the emission origination. Normally, the emission origination of CQDs can be divided into two categories: one is intrinsic state related to conjugated $\pi$-domains in CQDs [22,23], the other is surface/defect/edge state related to the surface groups or defects [24-27]. However, carbon cores, surface states and defect states usually coexist in the as-prepared CQDs and all of them contribute to the photoluminescence process. Unfortunately, the synergy or competition mechanism between intrinsic states and surface/defect states is difficult to be revealed due to its complex characteristic, especially the quantum confinement effect is introduced into the CQDs series at the same time, which needs pay more efforts for the researchers to explore the detailed mechanism.

Chlorine was introduced into carbon materials for the first time by Yang group at 2013 [28]. They realized the multicolor emission in chlorine-doped CQDs and attributed such novel optical properties to the additional energy levels between $C \pi$ and $C \pi *$ introduced by $C l$ dopants. Zhao et al. [29] then fabricated the chlorine doped CQDs by way of the chemical exfoliation of $\mathrm{HCl}$ treated carbon fibers and the related photovoltaic detectors exhibited an exceptionally big ratio of photocurrent to dark current as high as $\sim 105$. Although chlorine doping can bring excellent application performance, the relative research works are rather rare due to the big radius mismatch between $\mathrm{Cl}$ and $\mathrm{C}$, especially for double heteroatoms co-doping. The investigation about double-heteroatom doping with $\mathrm{Cl}$ as one kind of dopant in CQDs is almost blank. Therefore, we aim to achieve the nitrogen and chlorine co-doped CQDs to tune the emission wavelength and further investigate co-doping effects on the luminescent properties of CQDs. Moreover, the luminescence mechanism of the CQDs is much vaguer after element doping, especially for co-doping CQDs, which means that the PL mechanism of CQDs is still an open topic. The detailed synergy and competition mechanism of carbon cores and surface/defect states during the photoluminescence process in such kind of CQDs is necessary to be revealed, which is beneficial for extending the application field and enhancing the application performance of CQDs.

In present work, nitrogen and chlorine co-doped CQDs with unique strong blue-green emission were synthesized through a facile and one-pot hydrothermal method with 1,2,4-benzentriamine dihydrochloride (BD) as nitrogen and chlorine sources. Crystalline and optical properties of CQDs have been well tuned by controlling the mole ratio of citric acid to BD and reaction time. The detailed synergy and competition of chlorine-related states and conjugated $\pi$-domain via gradually varied concentration of nitrogen and chlorine dopants has been discussed in detail.

\section{Experimental}

\subsection{Materials}

All the chemicals were utilized without any further purification. Monohydrate citric acid (CA) was purchased from Beijing Chemical Works (Beijing, China). 1,2,4-Benzeneetriamine dihydrochloride (BD) was purchased from Energy Chemical (Shanghai, China), the deionized water was purified using a Millipore (Shanghai, China) system throughout all experiments. 


\subsection{Synthesis of $\mathrm{N}, \mathrm{Cl}$ Co-Doped CQDs}

In comparison with counterpart bulk composites, the nanostructured materials equipped with large surface area demonstrate the superior optical, magnetic and electrical characteristics [28-41]. The N,Cl co-doped CQDs were prepared by a novel and one-pot hydrothermal method: The certain quantity of $\mathrm{CA}$ and $\mathrm{BD}$ were dissolved in $10 \mathrm{~mL}$ deionized water with well-stirring to form a transparent solution. Thereafter, the transparent solution was transferred into a $50 \mathrm{~mL}$ Teflon-lined stainless-steel autoclave. The autoclave was kept in an electric oven under $200{ }^{\circ} \mathrm{C}$ with different duration time. The collected CQDs were dialyzed for $24 \mathrm{~h}$ in deionized water with the molecular weight cut-off (MWCO) dialysis bag of $3000 \mathrm{Da}$ and then further dialyzed for $12 \mathrm{~h}$ in deionized water using a MWCO of $3500 \mathrm{Da}$. Finally, vacuum-rotary evaporation was performed to remove the water. The obtained CQDs powder can be easily redispersed in water with a certain concentration to set aside for subsequent characterization. In this work, two sets of CQDs were synthesized. One set was prepared by varying the reactant molar concentration ratio of $C A$ and $B D$ for 1:0.5, 1:1, 1:1.5 and 1:2 for reacting $24 \mathrm{~h}$. CA was added at $0.4204 \mathrm{~g}(2 \mathrm{mmol})$ and $0.1961 \mathrm{~g}(1 \mathrm{mmol}), 0.3923 \mathrm{~g}(2 \mathrm{mmol}), 0.5884 \mathrm{~g}$ ( $3 \mathrm{mmol}$ ) and $0.7845 \mathrm{~g}(4 \mathrm{mmol})$ of BD was added, respectively. The corresponding samples were then names as CQDs (1:0.5), CQDs (1:1), CQDs (1:1.5) and CQDs (1:2), respectively. The other set of samples was prepared by prolonging the reaction duration for $6 \mathrm{~h}, 12 \mathrm{~h}, 24 \mathrm{~h}, 36 \mathrm{~h}$ or $48 \mathrm{~h}$ with maintaining the reactant molar concentration ratio of $\mathrm{CA}$ and $\mathrm{BD}$ for 1:1. The corresponding samples were then names as CQDs (6 h), CQDs (12 h), CQDs (24 h), CQDs (36 h) and CQDs (48 h), respectively.

The scheme image of synthetic process of CQDs in our case is shown in Figure 1. Under the hydrothermal conditions, $\mathrm{CA}$ and BD undergoes dehydration. During this process, hydrochloric acid will dissociate $\mathrm{H}^{+}$, so that chlorine will enter the CQDs in one step. Meanwhile, we discovered that an $\mathrm{N}$ atom enters CQDs by forming a pyrrolic structure through intramolecular dehydroxylation between neighboring carboxyl groups. Pyrrolic $\mathrm{N}$ is gradually transferred into quaternary $\mathrm{N}$ in the graphene with increasing the reaction time [42].

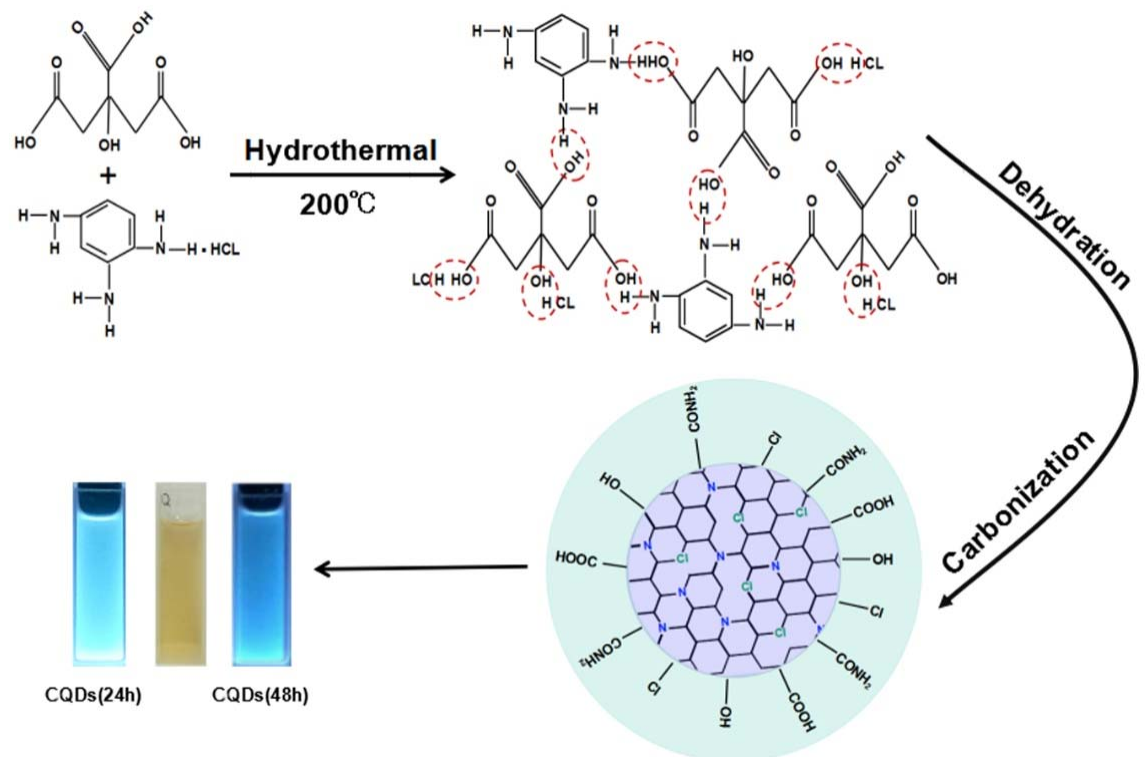

Figure 1. The scheme image of synthetic process of nitrogen and chlorine co-doped carbon quantum dots (CQDs).

\subsection{Characterization}

Transmission electron microscope (TEM) and high-resolution TEM images were performed with JEM-2100 electron microscope (JEOL Ltd., Tokyo, Japan) at an operating voltage of $200 \mathrm{kV}$. The atomic force microscopy (AFM) images were obtained on an Agilent 5500 SPM (Agilent Technologies Inc., 
Santa Clara, CA, USA) in AC mode with a silicon probe (NT-MDT, cantilever force constant $40 \mathrm{~N} \mathrm{~m}^{-1}$ ). Dynamic light scattering (DLS) was detected using a Nano-ZS (Malvern Instruments, Malvern, UK). Raman spectra were obtained from an inVia ${ }^{\mathrm{TM}}$ confocal Raman microscope of Renishaw with $514 \mathrm{~nm}$ wavelength excitation laser (Renishaw, London, UK). The X-ray photoelectron spectroscopy (XPS) was performed using an $\mathrm{Al} \mathrm{K} \alpha$ monochromatized source (Thermo Fisher Scientific, Waltham, MA, USA) to acquire elemental information. Fourier-transform infrared (FT-IR) spectra of CQDs were recorded using $\mathrm{KBr}$ pellets with a Bruker Vertex 70 spectrometer (Bruker, Billerica, Massachusetts, US) from 4000 to $400 \mathrm{~cm}^{-1}$. The ultraviolet-visible absorption spectra were obtained by UV-3600PC UV-Vis spectrophotometer of SHIMADZU Corp. (Shimadzu, Tokyo, Japan). The photoluminescence spectrum was recorded on a FL-1000 luminescence spectrometer (iHR320, Horiba Jobin Yvon, Paris, France) at room temperature in an aqueous solution. Time-resolved PL behavior was measured via the time-correlated single-photon counting (TCSPC) technique (Horiba Jobin Yvon, Paris, France).

\section{Results and Discussion}

\subsection{Effects of Reagent Ratio}

From dedicated structural characterization perspectives, TEM measurement is an effective methodology for structure research in the materials science and materials engineering [43-56]. The TEM technique was further utilized to characterize the microstructure and particle size of CQDs. The TEM images of CQDs (1:1) and CQDs (1:2) are shown in Figure 2a,c. Both as-prepared CQDs exhibit uniform dispersion without apparent aggregation. The HR-TEM images of CQDs (1:1) and CQDs (1:2) (insets in Figure 2a,c) illustrate the distance between the lattice fringes is about $0.20 \mathrm{~nm}$ and $0.23 \mathrm{~nm}$, respectively, which is close to $(100)$ facet of graphite [57,58]. Figure $2 b$,d illustrates the particle size distribution of CQDs (1:1) and CQDs (1:2). The mean diameter can be determined to be $2.5 \mathrm{~nm}$ and $3.3 \mathrm{~nm}$, respectively. Obviously, the particle size of CQDs (1:2) is enlarged with the increase of $\mathrm{BD}$ amount and the distance between particles is much closer than that of CQDs (1:1) as shown in the insets of Figure 2b,d. During the hydrothermal process, in comparison with CQDs (1:1), the increase of $\pi$-conjugate area due to the increase of the BD amount leads to the size enlargement of CQDs (1:2). Meanwhile, due to the amount of benzene rings and chlorine increased simultaneously, chlorine and nitrogen got more opportunity to enter the carbon core, so that the lattice fringes increase accordingly.

The atomic force microscopy (AFM) and Dynamic light scattering (DLS) techniques were further demonstrates the topographic morphology and particle distribution of the CQDs. The corresponding AFM images are shown in Figure 3. The typical topographic height of CQDs (1:1) and CQDs (1:2) is ca. $0.5-2.5 \mathrm{~nm}$ and $2-5 \mathrm{~nm}$, respectively, suggesting that the CQDs (1:1) consists of ca. 1-5 graphene layers and CQDs (1:2) consists of 4-10 graphene layers, which is also consistent with previous reports [59-62]. DLS further characterizes the distribution of CQDs in aqueous solution. The average particle size of the CQDs (1:1) and CQDs (1:2) is $5.47 \mathrm{~nm}$ and $7.3 \mathrm{~nm}$, respectively. DLS measurements indicated that the average particle size of the CQDs nanoparticles become a little bigger than that of the TEM characterization, which is reasonable since DLS characterizes the particle size of the CQDs in the hydrated state. Thus, we can confirm that the as-prepared CQDs in our case are carbon quantum dots.

Raman spectroscopy was used to further demonstrate the intrinsic structure of CQDs. The Raman spectra of CQDs (1:1) and CQDs (1:2) are shown in Figure 4. Both Raman spectra of samples exhibit two Raman peaks: one peak located at $\sim 1360 \mathrm{~cm}^{-1}$ can be ascribed to defect-related D-band, the other peak located at $\sim 1580 \mathrm{~cm}^{-1}$ can be ascribed to G-band related to $\mathrm{sp}^{2}$ carbon networks. The intensity ratio of $\mathrm{D}$ and $\mathrm{G}$ band $\left(\mathrm{I}_{\mathrm{D}} / \mathrm{I}_{\mathrm{G}}\right)$ is usually used to represent the degree of carbonization and defects of CQDs and the larger value of $\mathrm{I}_{\mathrm{D}} / \mathrm{I}_{\mathrm{G}}$ indicates the low degree of carbonization and more defects [63]. Gu et al. reported that doping heteroatom to CQDs can introduce more defects in the graphene lattice and change the lattice fringes of CQDs [64]. In our case, the particle size and lattice fringes of CQDs (1:2) increased compared to CQDs (1:1) and the value of $\mathrm{I}_{\mathrm{D}} / \mathrm{I}_{\mathrm{G}}$ for CQDs (1:1) and CQDs (1:2) is calculated to be 0.52 and 0.78 , respectively. Thus, the increased $\mathrm{I}_{\mathrm{D}} / \mathrm{I}_{\mathrm{G}}$ ratio for CQDs $(1: 2)$ can be attributed to 
the appearance of more defects caused by introducing more nitrogen and chlorine into CQDs (1:2). Moreover, compared to the Raman spectrum of CQDs (1:1), the peak position of the D-band in CQDs (1:2) kept stay, while the position of G-band shifted to lower wavenumber by $10 \mathrm{~cm}^{-1}$, which can be attributed to the phonon stiffening in CQDs $(1: 2)[65,66]$.

The information of surface functional group can be obtained by Fourier transform infrared (FTIR) spectra. Figure 5 illustrated the FTIR spectra of CQDs (1:0.5), CQDs (1:1), CQDs (1:1.5) and CQDs (1:2). All FTIR spectra demonstrate two strong absorption band located at $1640 \mathrm{~cm}^{-1}$ and $1400 \mathrm{~cm}^{-1}$, which can be ascribed to the strong stretching vibrations of $\mathrm{C}=\mathrm{C}$ and $\mathrm{C}-\mathrm{N}$, respectively. Meanwhile, broad absorption bands at $3000-3600 \mathrm{~cm}^{-1}$ can be attributed to $\mathrm{C}-\mathrm{OH}$ and $\mathrm{N}-\mathrm{H}$ stretching vibrations, respectively. It is interesting to observe another absorption band located at $600-800 \mathrm{~cm}^{-1}$, which can be assigned to $\mathrm{C}-\mathrm{Cl}$ vibration mode, indicating chlorine has been successfully doped into CQDs $[19,67,68]$.
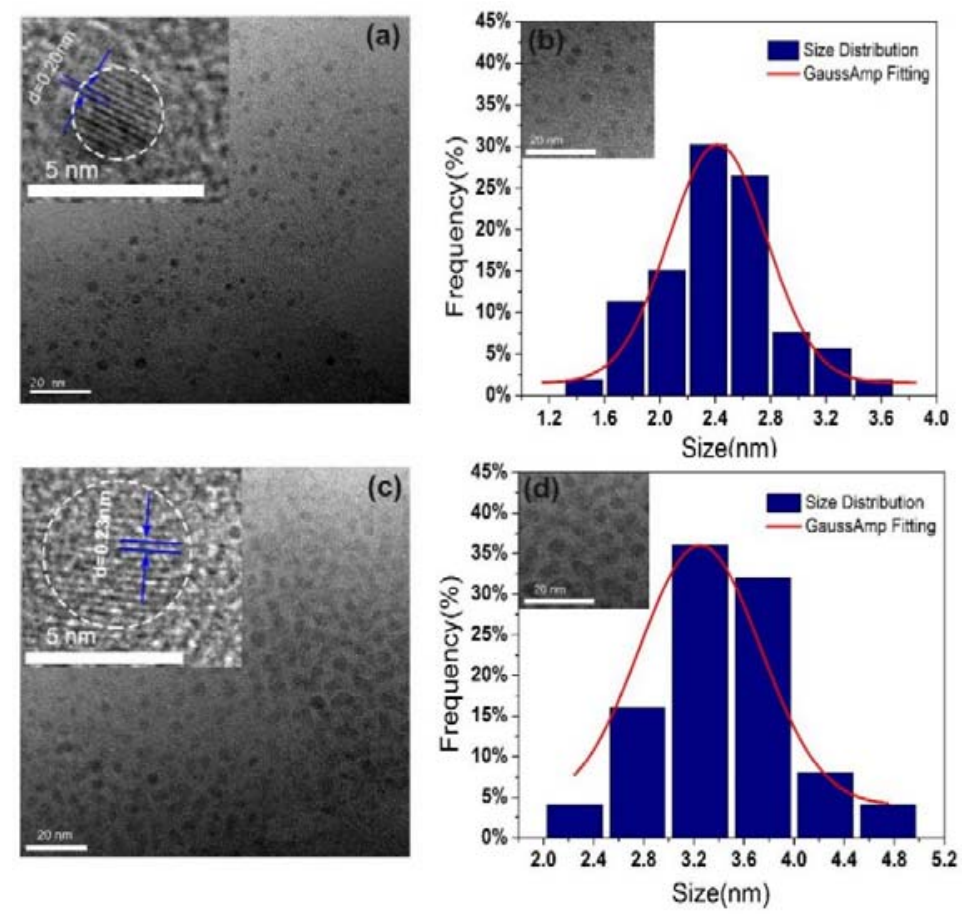

Figure 2. (a,c) Transmission electron microscopy (TEM) and high-resolution TEM (HRTEM) (insert) images of CQDs (1:1) and CQDs (1:2); (b,d) The size distribution and local-enlarged TEM image (inset) of the CQDs (1:1) and CQDs (1:2).

X-ray photoelectron spectroscopy (XPS) was further utilized to obtain the functional group and chemical composition information of CQDs. Figure 6 presented the high-resolution C 1s, $\mathrm{N} 1 \mathrm{~s}, \mathrm{O} 1 \mathrm{~s}$ and Cl 2p core levels XPS spectra of CQDs (1:0.5), CQDs (1:1), CQDs (1:1.5) and CQDs (1:2) samples. As shown in Figure $6 \mathrm{a}, \mathrm{e}, \mathrm{i}, \mathrm{m}$, four peaks are necessary for well-fitting C 1s XPS spectra, indicating four carbon species exist in CQDs samples. The fitting peaks are located at $284.5 \mathrm{eV}$ and $288.2 \mathrm{eV}$, which can be attributed to $\mathrm{C}=\mathrm{C}$ and $\mathrm{C}=\mathrm{O} / \mathrm{C}-\mathrm{O}$ bond, respectively [28,69-71]. Meanwhile, another two fitting peaks are located at $285.5 \mathrm{eV}$ and $286.6 \mathrm{eV}$, which can be assigned to $\mathrm{C}-\mathrm{N}$ and $\mathrm{C}-\mathrm{Cl}$ bond [72,73], respectively. It is consistent with the results of FTIR, which further proves nitrogen and chlorine have been successfully introduced into CQDs. With varying the ratio of CA:BD from 1:0.5 to 1:2, the content of chlorine and nitrogen continuously increased and reach to the maximum when the ratio of CA and $\mathrm{BD}$ is 1:2. The high-resolution $\mathrm{O} 1 \mathrm{~s}$ spectra are shown in Figure 6c,g,k,o. The two fitted peaks at 531.3 and $532.4 \mathrm{eV}$ are ascribed to $\mathrm{C}=\mathrm{O}$ and $\mathrm{C}-\mathrm{O}$ groups [74,75], respectively. The existence of $\mathrm{C}-\mathrm{O}$ and $\mathrm{C}=\mathrm{O}$ bonds indicated that the surface of the as-synthesized CQDs is functionalized by multiple oxygenated groups, which is consistent with $\mathrm{C} 1 \mathrm{~s}$ spectra. The $\mathrm{C} / \mathrm{O}$ atomic ratio for the CQDs (1:0.5), CQDs (1:1), 
CQDs (1:1.5) and CQDs (1:2) is 1.34, 1.49, 1.89 and 3.2, respectively. The increased C/O ratio is related to the amount of BD. With increasing BD from $0.5 \mathrm{mmol}$ to $2 \mathrm{mmol}$, the content of carbon increased at the same time, so that the $\mathrm{C} / \mathrm{O}$ becomes larger. To testify the continuously increase of $\mathrm{Cl}$ and $\mathrm{N}$ doping concentration, the high-resolution $\mathrm{N} 1 \mathrm{~s}$ and $\mathrm{Cl} 2 \mathrm{p}$ core level XPS spectra of CQDs (1:0.5), CQDs (1:1), CQDs (1:1.5) and CQDs (1:2) samples are shown in Figure 6b,f,j,n and Figure 6d,h,l,p. The binding energy located at $\sim 399.4 \mathrm{eV}$ and $\sim 400.4 \mathrm{eV}$ can be attributed to pyrrolic $\mathrm{N}$ and graphitic $\mathrm{N}$, respectively. The binding energy located at $198 \mathrm{eV}$ and $202 \mathrm{eV}$ can be assigned to $\mathrm{Cl} 2 \mathrm{p}^{1 / 2}$ and $\mathrm{Cl} 2 \mathrm{p}^{3 / 2}$ core lines, respectively. Obviously, with varying the ratio of $\mathrm{CA}: \mathrm{BD}$ from 1:0.5 to 1:2, the content of graphitic $\mathrm{N}$ and the signal intensity of $\mathrm{Cl} 2 \mathrm{p}$ continuously increases and the peak shape of $\mathrm{Cl} 2 \mathrm{p}$ gradually turns better, indicating that the doping concentration of chlorine increases. The percentages of $\mathrm{C}-\mathrm{N}$ and $\mathrm{C}-\mathrm{Cl}$ bond of four samples are listed in Table 1.
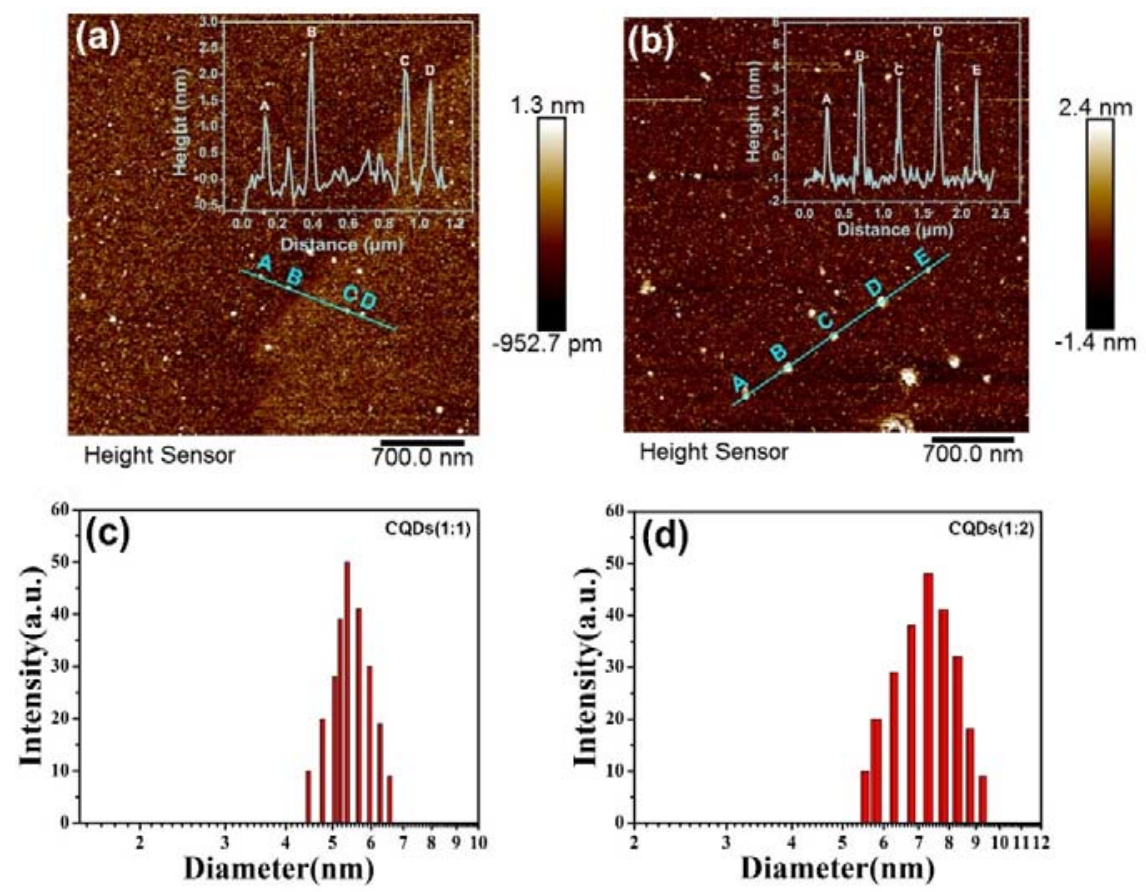

Figure 3. (a,b) Atomic force microscopy (AFM) images of CQDs (1:1) and CQDs (1:2) deposited on a silicon slice (inset: the height profile along the line in the topographic image of the CQDs (1:1) and CQDs (1:2), respectively); (c,d) Dynamic light scattering (DLS) images of CQDs (1:1) and CQDs (1:2).

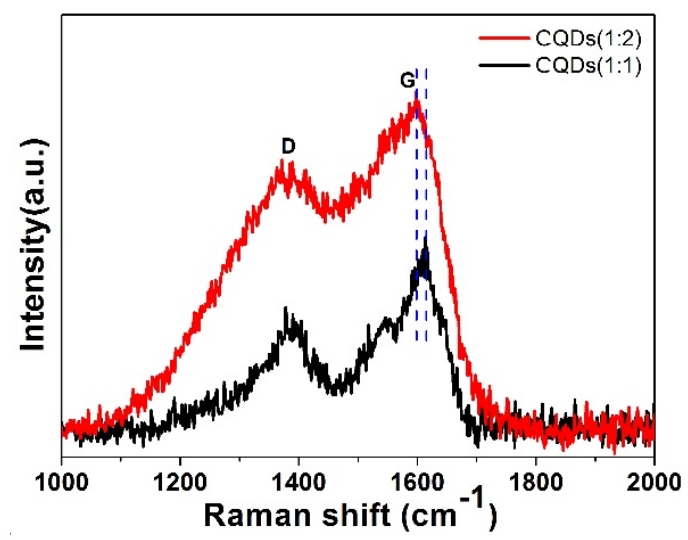

Figure 4. Raman spectra $\left(\lambda_{\mathrm{ex}}=514 \mathrm{~nm}\right)$ of CQDs (1:1) and CQDs (1:2). 

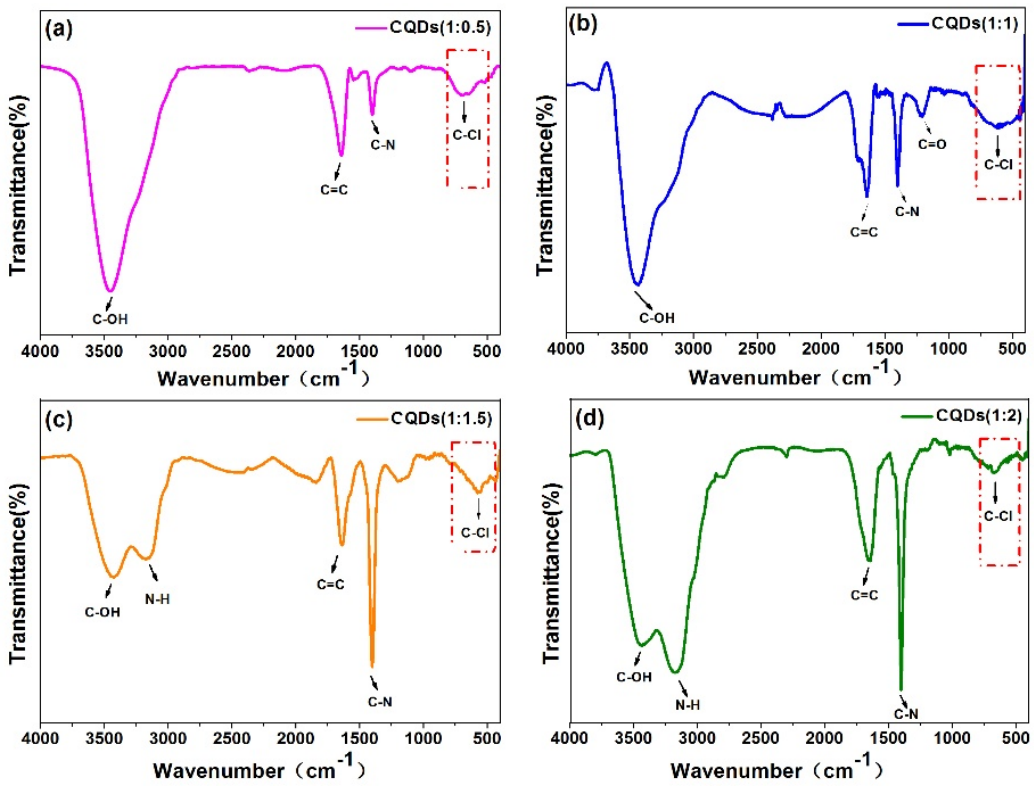

Figure 5. Fourier transform infrared (FTIR) spectra of CQDs (1:0.5) (a), CQDs (1:1) (b), CQDs (1:1.5) (c) and CQDs (1:2) (d).
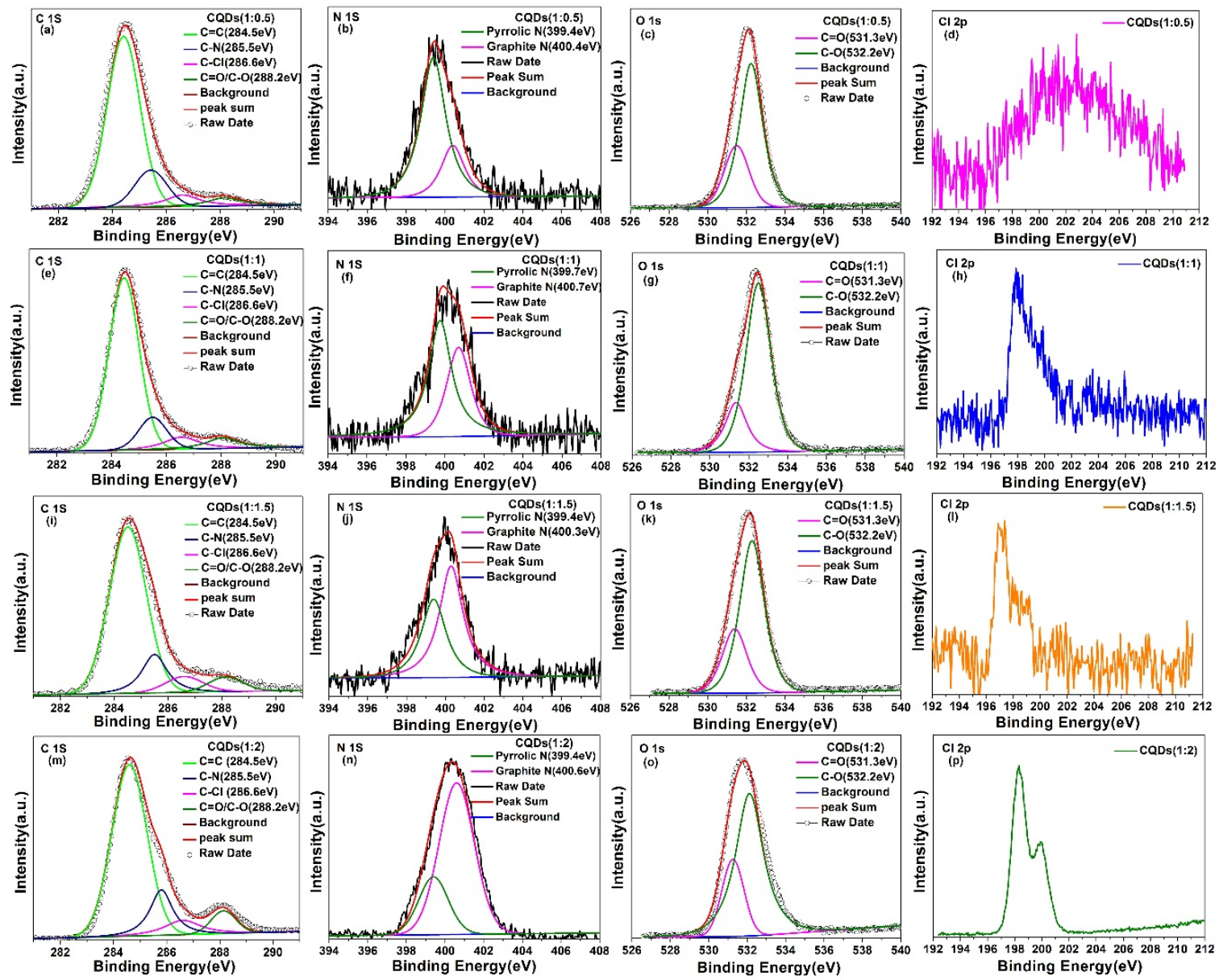

Figure 6. High-resolution $\mathrm{C} \mathrm{1s,} \mathrm{N} \mathrm{1s,} \mathrm{O} \mathrm{1s} \mathrm{and} \mathrm{Cl} \mathrm{2p} \mathrm{core} \mathrm{level} \mathrm{X-ray} \mathrm{photoelectron} \mathrm{spectroscopy} \mathrm{(XPS)}$ spectra of CQDs (1:0.5) (a-d), CQDs (1:1) (e-h), CQDs (1:1.5) (i-1) and CQDs (1:2) (m-p). 
Table 1. Intensity proportion of $\mathrm{C}-\mathrm{N}$ and $\mathrm{C}-\mathrm{Cl}$ in the $\mathrm{C}$ 1s spectra of CQDs (1:0.5), CQDs (1:1), CQDs (1:1.5) and CQDs (1:2).

\begin{tabular}{ccccc}
\hline Sample & CQDs (1:0.5) & CQDs (1:1) & CQDs (1:1.5) & CQDs (1:2) \\
\hline C-N & $2.92 \%$ & $4.46 \%$ & $6.42 \%$ & $10.96 \%$ \\
C-Cl & $1.08 \%$ & $1.94 \%$ & $2.86 \%$ & $4.10 \%$ \\
\hline
\end{tabular}

Taking account to the results obtained from TEM, Raman, XPS and FTIR spectra, two important facts for CQDs in our case can be extracted. The $\mathrm{N}, \mathrm{Cl}$ co-doped CQDs can be successfully synthesized with much higher degree of carbonization compared with other reports [76-79] and the nitrogen and chlorine doping concentration can be well controlled by adjusting the precursor ratio of CA:BD. Secondly, the existence of $\mathrm{C}-\mathrm{Cl}$ and $\mathrm{C}-\mathrm{N}$ bond and its corresponding concentration in CQDs exhibited great influence on the degree of carbonization of CQDs, implying that the introduction of nitrogen and chlorine might significantly affect the luminescent properties of CQDs.

In order to clarify the influence mechanism of reactants ratio on the optical properties of $\mathrm{N}$, $\mathrm{Cl}$ co-doped CQDs, their absorption and photoluminescence properties have been studied in detail. Figure 7a displays the ultraviolet-visible (UV-Vis) absorption spectra of CQDs (1:0.5), CQDs (1:1), CQDs (1:1.5) and CQDs (1:2) samples. All spectra exhibit three absorption peaks located at $\sim 225 \mathrm{~nm}, \sim 260 \mathrm{~nm}$ and $\sim 292 \mathrm{~nm}$, which corresponds to $\pi-\pi^{*}$ transition of $\mathrm{C}=\mathrm{C}$ bond, $\mathrm{C}=\mathrm{N}$ bond and Cl-related state in N, $\mathrm{Cl}$ co-doped CQDs, respectively [80,81]. Obviously, the absorption spectra exhibit great dependence on the reactants ratio of CA:BD. For the absorption peak located at $225 \mathrm{~nm}$, as compared to CQDs (1:0.5), a slight hyperchromic effect can be observed in CQDs (1:1) and then turns into obvious hypochromic effect for CQDs (1:1.5) and CQDs (1:2) samples. The hyperchromic effect is probably related to the increased conjugate $\pi$-domain due to adding more $\mathrm{BD}$ in the reaction. Once the reagent of $\mathrm{BD}$ continues to increase, the enlarged particle size of CQDs reduced the distance between CQDs (as shown in Figure 2), so that the $\pi-\pi$ interaction can be effectively occurred, which finally resulted in hypochromic effect $[82,83]$. Moreover, Noor-Ul-Ain reported doping chlorine into CQDs would introduce additional energy level between the $\mathrm{C}_{\pi}-\mathrm{C}_{\pi}{ }^{*}$, called the Cl-related states [84]. The corresponding absorption peak at $292 \mathrm{~nm}$ observed in our samples coincided with the calculated transition energy from $C_{\pi}$ to Cl-related states [28,69]. The absorption intensity of $292 \mathrm{~nm}$ peak exhibits a similar variation tendency via reactants ratio of CA:BD in comparison with $225 \mathrm{~nm}$ absorption peak, implying Cl-related states might play a great role in the photoluminescence process. It is worth pointing out here that usually the $\mathrm{C}=\mathrm{O}$ contributes to the luminescence process of CQDs $[85,86]$. As shown in the XPS and FTIR spectra above, a relative small content of $\mathrm{C}=\mathrm{O}$ bond can be observed but a large number of $\mathrm{C}-\mathrm{O}$ exists in the form of $\mathrm{C}-\mathrm{OH}[78,79]$. What needs to be explained is that the amount of $\mathrm{C}-\mathrm{OH}$ is depending on the degree of dryness of the sample during the characterization, since the CQDs are stored in an aqueous solution, the aqueous solution contains a large amount of $\mathrm{C}-\mathrm{OH}$. According to the previous reports, the typical absorption peak of $\mathrm{C}=\mathrm{O}$ are usually located at 300-400 $\mathrm{nm}[85,86]$. However, no absorption peak at the region of $300-400 \mathrm{~nm}$ appeared in our case, implying that $\mathrm{C}-\mathrm{O} / \mathrm{C}=\mathrm{O}$ did not play a leading role in the luminescence process of CQDs.

Figure $7 \mathrm{~b}$ shows the excitation wavelength-dependent photoluminescence (PL) spectra of CQDs (1:1). As shown in Figure 7b, a characteristic green emission at $512 \mathrm{~nm}$ and a shoulder blue emission at $466 \mathrm{~nm}$ can be observed in Figure $7 \mathrm{~b}$. The blue emission located at $466 \mathrm{~nm}$ is usually assigned to the conjugated $\pi$-domain including $\mathrm{C}=\mathrm{C}$ or $\mathrm{C}=\mathrm{N}[17,87]$. Obviously, the green emission centered at $\sim 512 \mathrm{~nm}$ is beyond emission wavelength region of conjugated $\pi$-domain $[17,87]$. According to the scheme image of synthetic process shown in Figure 1, only $\mathrm{Cl}$ exists in the CQDs beside $\mathrm{C}$ and $\mathrm{N}$ groups. Moreover, an absorption peak corresponding to $\mathrm{Cl}$-related states appeared in Figure 7a. Therefore, it is reasonable to deduce that this main green emission in $\mathrm{N}, \mathrm{Cl}$ co-doped CQDs is probably related to the Cl-states [28]. No excitation wavelength dependence for $466 \mathrm{~nm}$ emission indicated the good crystallization quality of CQDs, which confirms the results of TEM and Raman measurement. 
Furthermore, it can be seen from Figure $7 \mathrm{~b}$, when the excitation wavelength increases from 380 to $440 \mathrm{~nm}$, the PL peaks exhibit slight excitation wavelength dependence from 512 to $522 \mathrm{~nm}$. Such excitation-dependent PL behavior of the CQDs is similar to the previous reports [88-90]. Wu et al. reported that the excitation-dependent emission is associated with the surface defects resulted from $\mathrm{C}-\mathrm{OH}$ and $\mathrm{C}=\mathrm{O}$ groups in the CQDs [90]. These $\mathrm{C}-\mathrm{OH}$ and $\mathrm{C}=\mathrm{O}$ groups form the emissive traps present on the CQDs surface. At certain excitation wavelengths, some of these emissive sites would be excited and fluoresce, giving rise to the induced dependent spectra. As for our as-prepared CQDs, a lot of oxygen-containing groups on the surface of $\mathrm{CQDs}$ such as $\mathrm{C}-\mathrm{OH}, \mathrm{C}=\mathrm{O}$ and $\mathrm{COOH}$ indeed testified by XPS and FTIR measurements. It is worth mentioning that, a portion of the $\mathrm{C}-\mathrm{OH}$ bond is derived from the air during the XPS test and another part of the $\mathrm{C}-\mathrm{OH}$ bond is attributed to the degree of dryness of the sample during the FTIR characterization, since the CQDs are stored in an aqueous solution. Some of these oxygen-containing groups could form "surface states" and results in excitation-dependent PL behavior of as-prepared CQDs. Figure 7c presents the PL spectra of CQDs (1:0.5), CQDs (1:1), CQDs (1:1.5) and CQDs (1:2) samples. The peak position of blue emission remained at $466 \mathrm{~nm}$ via tuning the ratio of CA:BD, further testifying that this emission was originated from the conjugated $\pi$-domain. The peak center of green emission for CQDs (1:0.5), CQDs (1:1), CQDs (1:1.5) and CQDs (1:2) are located at $507 \mathrm{~nm}, 511 \mathrm{~nm}, 507 \mathrm{~nm}$ and $491 \mathrm{~nm}$, respectively. Obviously, this green emission firstly exhibits slight red-shift and then turns into blue-shift as shown in the inset of Figure $7 c$, which might be ascribed to the competition of chlorine-related states, quantum confinement effect (QCE) and conjugated $\pi$-domain. In detail, Bolton O. reported that red-shift takes place in the emission wavelength once halogen elements such as chlorine are introduced into CQDs [91]. Graphene is a single atomic layer of graphite with an infinite exciton Bohr radius due to its linear energy dispersion relation of the charge carriers, resulting in QCE for graphene of any finite size [92]. Meanwhile, under the function of QCE, increased size can increase the band gap to achieve red-shift of luminescence $[93,94]$. The above two reasons might be the reason for the red shift of CQDs (1:1) compared to the CQDs (1:0.5), since more $\mathrm{Cl}$ has been introduced into the CQDs and QCE start to work. But CQDs (1:2) exhibits a slight blue-shift compared to CQDs (1:0.5) CQDs (1:1.5). Since the atom ratio of $\mathrm{N}: \mathrm{Cl}$ is 3 in the $\mathrm{BD}$ molecular formula, the increase amplitude of nitrogen is much larger than that of chlorine in CQDs. Li et al. reported nitrogen atoms in CQDs could contribute to the blue-shift of luminescence center [95]. However, the size difference between CQDs (1:2) and CQDs (1:1) is only $0.8 \mathrm{~nm}$. The QCE might be covered up by much more nitrogen introduction, so that a slight blue-shift was observed. Thus, it is reasonable for us to believe that due to the competition between the conjugated $\pi$-domain, quantum confinement effect and chlorine-related states, the green emissions for CQDs (1:1.5) and CQDs (1:2) exhibit obvious blue-shift in comparison to that of CQDs (1:1).

Fluorescence lifetime is important information to reveal the carrier behavior. Figure $7 \mathrm{~d}$ presents the TRPL spectra of CQDs (1:0.5), CQDs (1:1) and CQDs (1:2) samples. All the PL decay curves of as-prepared CQDs can be well fitted by double-exponential function: $I(t)=A_{1} \exp \left(-t / \tau_{1}\right)+A_{2} \exp$ $\left(-t / \tau_{2}\right)$, where $\tau_{1}$ and $\tau_{2}$ are the time constants of the two radiation decay channels; $A_{1}$ and $A_{2}$ are the corresponding amplitudes. The involved lifetimes of $\tau_{1}$ and $\tau_{2}$ have been summarized in Table 2, which is analogous to other reported values [96]. The double-exponential function decay curves for with fast and slow decay components all the CQDs revealed that all of samples have two luminescence pathways. According to the previous reports, the emission originated from defect states showed a longer recombination lifetime than that from intrinsic states [97-100]. Thus, the longer lifetime of CQDs in our case was attributed to the chlorine-related states [101] and the shorter lifetime corresponds to the conjugated $\pi$-domains (intrinsic state). When the ratio of CA:BD changes from 1:0.5 to 1:2, the doping amount of nitrogen and chlorine are increasing at the same time. Meanwhile, the conjugated $\pi$-domains have also grown, which is confirmed by the TEM image. Thus, the lifetime of $\tau_{1}, \tau_{2}$ and average lifetime exhibit an increasing trend in Table 2. 

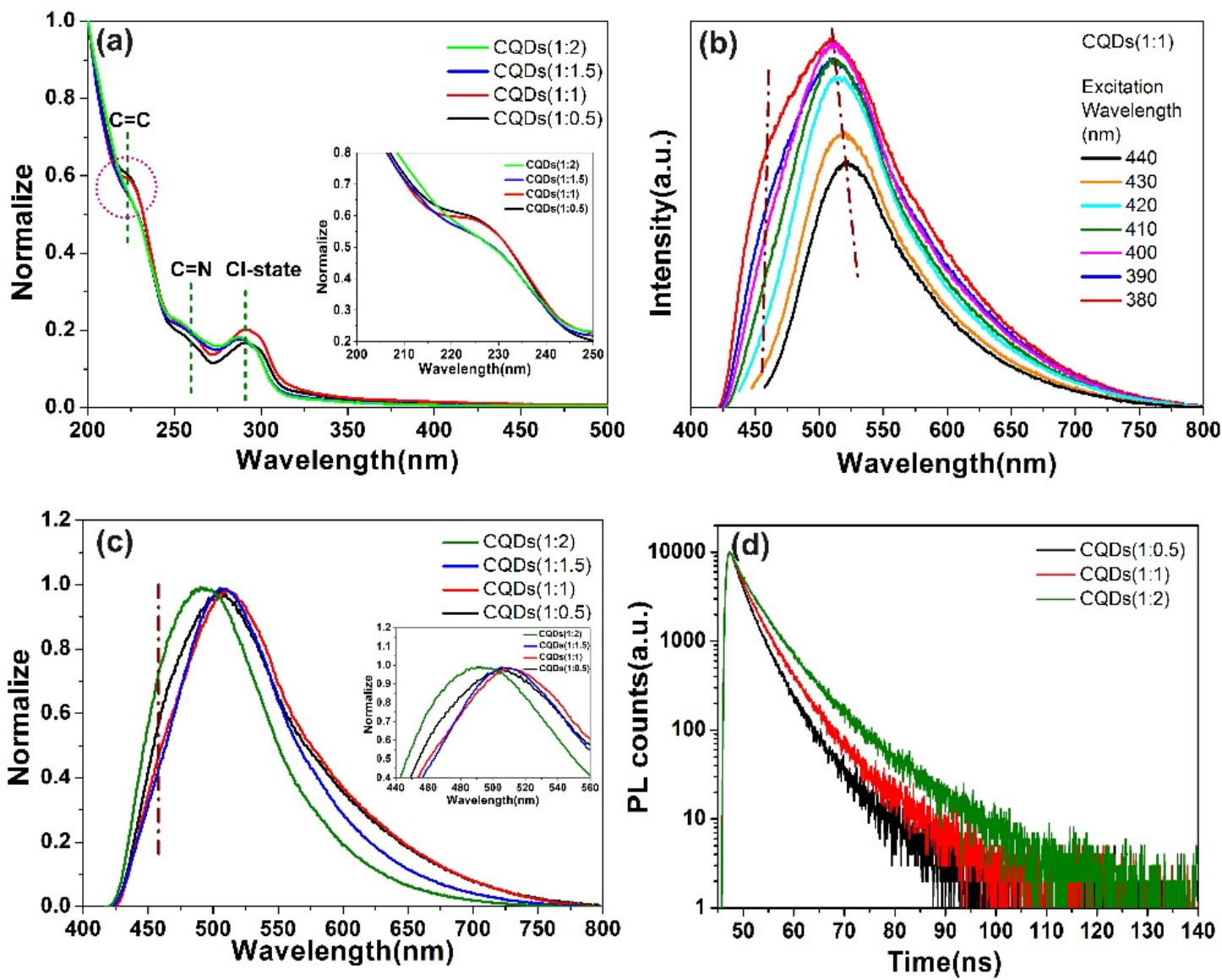

Figure 7. (a) UV-Vis absorption spectra of CQDs (1:0.5), CQDs (1:1), CQDs (1:1.5) and CQDs (1:2) in aqueous solutions (The inset is an enlarged view of absorbed by $\mathrm{C}=\mathrm{C}$ ); (b) PL spectra of CQDs (1:1) excited at wavelength of 380-440 nm, with increments of $10 \mathrm{~nm}$; (c) PL spectra of CQDs (1:0.5), CQDs (1:1), CQDs (1:1.5) and CQDs (1:2) in aqueous solutions (The inset is an enlarged view of emission area in the range of $440 \mathrm{~nm}-550 \mathrm{~nm}$ ); (d) PL decay curves of CQDs under excitation wavelength of $400 \mathrm{~nm}$.

Table 2. The lifetime components of CQDs (1:0.5), CQDs (1:1) and CQDs (1:2).

\begin{tabular}{ccccc}
\hline Sample & $\tau_{\mathbf{1}}$ (ns) & $\tau_{\mathbf{2}}$ (ns) & $\tau_{\text {average }}($ ns) & $\chi^{\mathbf{2}}$ \\
\hline CQDs (1:0.5) & 2.21 & 5.56 & 2.75 & 0.93 \\
CQDs (1:1) & 2.46 & 6.11 & 3.32 & 1.05 \\
CQDs (1:2) & 3.08 & 7.97 & 4.23 & 0.86 \\
\hline
\end{tabular}

\subsection{Effects of Reaction Time}

To further reveal the effects of chlorine and nitrogen cooperation on the structure and optical properties of CQDs, the reaction time has been adjusted with keeping ratio as a constant of 1:1 and a set of samples of CQDs (6 h), CQDs (12 h), CQDs (24 h), CQDs (36 h) and CQDs (48 h) have been synthesized. The TEM and HRTEM images of CQDs ( $24 \mathrm{~h})$ and CQDs (48 h) are shown in Figure 8. The description of TEM and HRTEM of CQDs $(24 \mathrm{~h})$ can be found in Figure 2a,b. As shown in Figure $8 \mathrm{c}, \mathrm{d}$, the as-prepared CQDs $(48 \mathrm{~h}$ ) is well-dispersed and the average particle size is $\sim 1.5 \mathrm{~nm}$, which is much smaller than those CQDs in recent reports [102,103]. The HRTEM image presented in the inset of Figure 8c shows the crystalline structure of CQDs (48h) and the distance between the lattice fringes is $0.22 \mathrm{~nm}$, which is consistent to (100) facet of graphite [104]. Through comparing CQDs (24 h) with CQDs (48 h), a phenomenon can be clearly found that the increase of reaction time can result in a smaller particle size and larger lattice fringes. As the reaction time is prolonged, more 
opportunities can be provided for nitrogen and chlorine to enter into the carbon core. Since the ion radius of $\mathrm{N}(1.29 \AA)$ and $\mathrm{Cl}(1.81 \AA)$ is larger than that of $\mathrm{C}(0.86 \AA)$, the lattice fringes of CQDs (48 h) are reasonable to be enlarged. In addition, the reduced size of CQDs ( $48 \mathrm{~h})$ indicated that chlorine and nitrogen have an inhibition effect on the particle growth of CQDs [105]. The AFM and DLS technique was further utilized to demonstrate the topographic morphology and particle distribution of the CQDs (48 h), which was shown in Figure 9a,b. The typical topographic height of CQDs (48 h) is $0.5-1.5 \mathrm{~nm}$, which indicated that the CQDs (48 h) consists of ca. 1-3 graphene layer. DLS further characterizes the distribution of CQDs in aqueous solution. The average particle size of the CQDs (48 h) is $4.48 \mathrm{~nm}$. It is bigger than the TEM results, which is reasonable since DLS characterizes the particle size of the CQDs in the hydrated state.
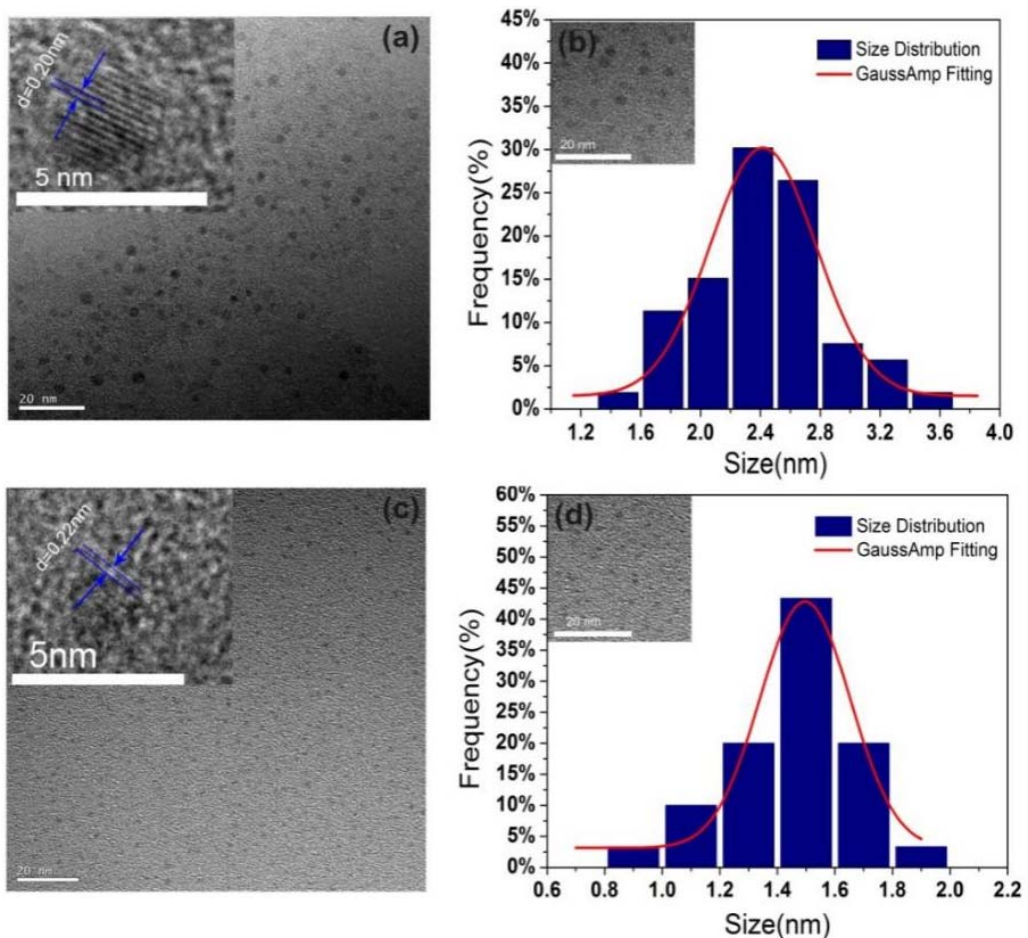

Figure 8. (a,c) TEM and HRTEM (the insert) images of CQDs (24 h) and CQDs (48 h); (b,d) The size distribution and local enlarged TEM image (inset) of the CQDs (24 h) and CQDs (48 h).
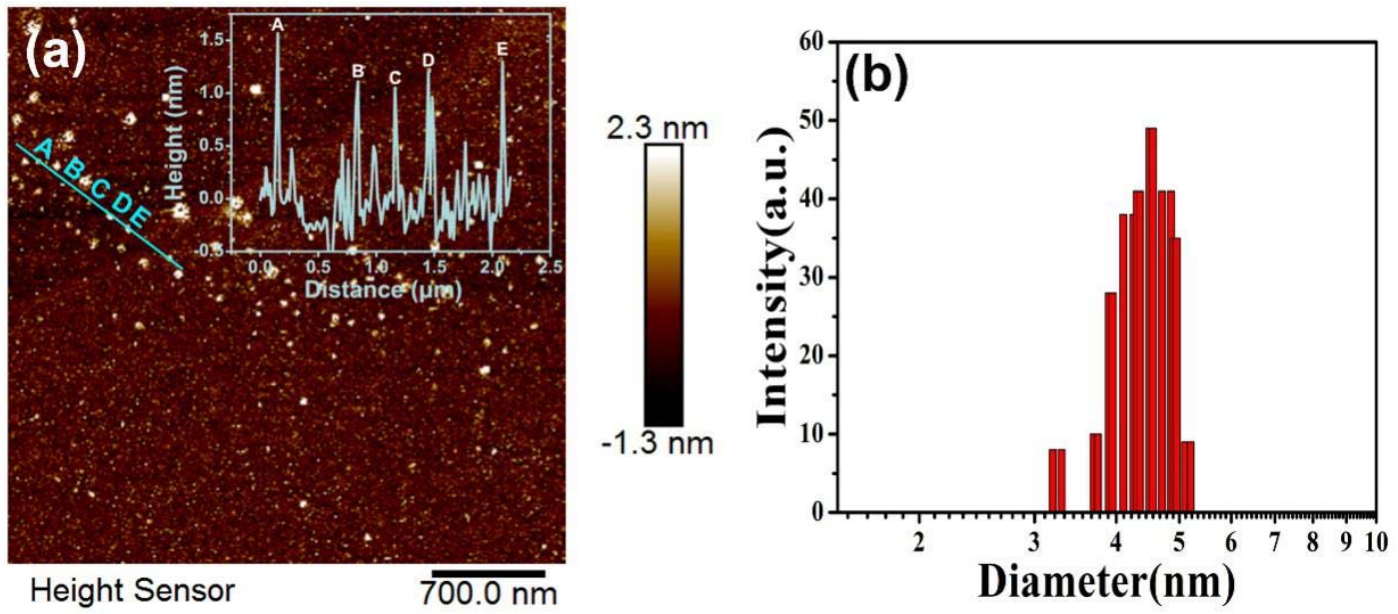

Figure 9. (a) AFM image of CQDs (48 h) deposited on a silicon slice (inset: the height profile along the line in the topographic image of the CQDs (48 h); (b) DLS image of CQDs (48 h). 
The Raman spectra $\left(\lambda_{\mathrm{ex}}=514 \mathrm{~nm}\right)$ of CQDs $(24 \mathrm{~h})$ and CQDs $(48 \mathrm{~h})$ are shown in Figure 10. Two Raman vibrational peaks at $1382 \mathrm{~cm}^{-1}$ and $1611 \mathrm{~cm}^{-1}$ can be assigned to the defect-related D-band and G-band related to sp2 carbon networks. The intensity ratio of the D band and G band $\left(\mathrm{I}_{\mathrm{D}} / \mathrm{I}_{\mathrm{G}}\right)$ is 0.52 and 0.62 for CQDs $(24 \mathrm{~h})$ and CQDs $(48 \mathrm{~h})$, respectively. The enlarged value of $\mathrm{I}_{\mathrm{D}} / \mathrm{I}_{\mathrm{G}}$ with prolonging the reaction time implied more defects appear in CQDs $(48 \mathrm{~h})$, indicating more nitrogen and chlorine have been incorporated into CQDs (48 h), which exhibits well agreement with the TEM results.

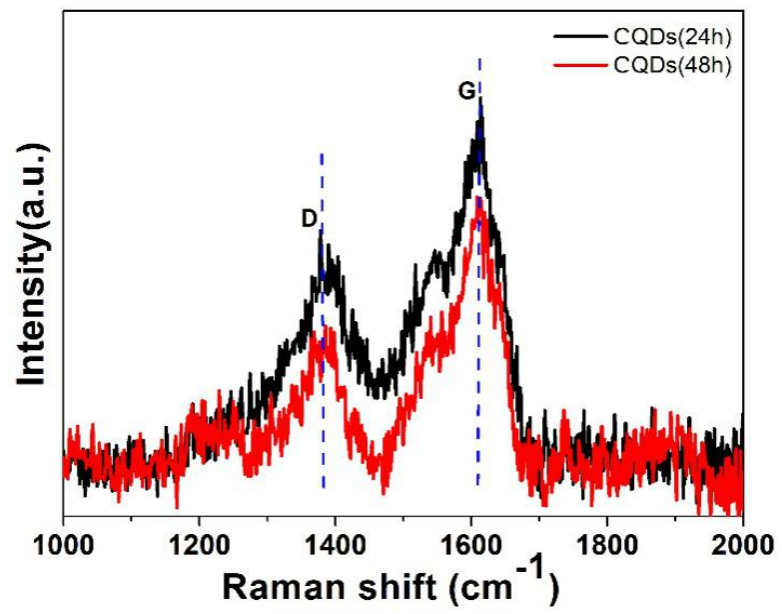

Figure 10. Raman spectra $\left(\lambda_{\mathrm{ex}}=514 \mathrm{~nm}\right)$ of CQDs $(24 \mathrm{~h})$ and CQDs $(48 \mathrm{~h})$.

The XPS technique was used to further investigate the effect of reaction time on the doping concentration of nitrogen and chlorine. The high-resolution XPS spectra of $\mathrm{C} 1 \mathrm{~s}, \mathrm{~N} 1 \mathrm{~s}, \mathrm{O} 1 \mathrm{~s}$ and $\mathrm{Cl} 2 \mathrm{p}$ for CQDs $(6 \mathrm{~h}), \mathrm{CQDs}(24 \mathrm{~h})$ and CQDs $(48 \mathrm{~h})$ are shown in Figure 11. Similar to Figure 6, four fitting peaks corresponding to the carbon in $\mathrm{C}=\mathrm{C}, \mathrm{C}-\mathrm{N}, \mathrm{C}-\mathrm{Cl}$ and $\mathrm{C}=\mathrm{O} / \mathrm{C}-\mathrm{O}$ located at 284.5 $\mathrm{eV}, 285.5 \mathrm{eV}, 286.6 \mathrm{eV}$ and $288.2 \mathrm{eV}$, respectively. Based on Figure 11a,e,i, the percentages of C-N and $\mathrm{C}-\mathrm{Cl}$ bonds in entire carbons for CQDs $(6 \mathrm{~h}), \mathrm{CQDs}(24 \mathrm{~h})$ and CQDs $(48 \mathrm{~h})$ are listed in Table 3. Obviously, the content of chlorine and nitrogen in CQDs exhibits a slight increase as the reaction time was prolonged from $6 \mathrm{~h}$ to $48 \mathrm{~h}$. As shown in Figure 11c,g, $\mathrm{k}$, the two fitted peaks of the high-resolution $\mathrm{O} 1$ s spectrum at 531.3 and $532.4 \mathrm{eV}$ are ascribed to $\mathrm{C}=\mathrm{O}$ and $\mathrm{C}-\mathrm{O}$ groups, respectively. The $\mathrm{C} / \mathrm{O}$ atomic ratio for the CQDs $(6 \mathrm{~h})$, CQDs $(24 \mathrm{~h})$ and CQDs $(48 \mathrm{~h})$ is 1.78, 1.49 and 2.5, respectively. It is worth mentioning that, hydrothermal reaction is carried out in a closed environment so that the content of the reactants is constant. When the reaction time is $6 \mathrm{~h}$, the reaction is incomplete and less oxygen-containing groups attached on the surface of CQDs $(6 \mathrm{~h})$. With extending the reaction time to $24 \mathrm{~h}$, more oxygen-containing functional groups owns enough time to attach on the surface of CQDs (24), so that the $\mathrm{C} / \mathrm{O}$ atomic ratio of CQDs $(24 \mathrm{~h})$ is smaller than CQDs $(6 \mathrm{~h})$. Further prolonging the reaction time to $48 \mathrm{~h}$, the CQDs can be purified to reduce some part of oxygen-containing functional groups on the surface of the CQDs $(48 \mathrm{~h})$, so that the $\mathrm{C} / \mathrm{O}$ atomic ratio of CQDs $(48 \mathrm{~h})$ turned larger again. The high-resolution $\mathrm{Cl} 2 \mathrm{p}$ and $\mathrm{N}$ 1s core level XPS spectra were further presented in Figure 11 to characterize the doping profiles of chlorine and nitrogen. The $\mathrm{Cl} 2 \mathrm{p}^{1 / 2}, \mathrm{Cl} 2 \mathrm{p}^{3 / 2}$, pyrrolic $\mathrm{N}$ and graphitic $\mathrm{N}$ are located at $198 \mathrm{eV}, 202 \mathrm{eV}, \sim 399.4 \mathrm{eV}$ and $\sim 400.4 \mathrm{eV}$, respectively. All these results testified that nitrogen and chlorine has been successfully introduced into CQDs. The signal intensity of $\mathrm{Cl} 2 \mathrm{p}$ spectra continuously increases and the shape of peak gradually turns better, indicating that the doping concentration of chlorine increases. Meanwhile, the intensity ratio of graphitic $\mathrm{N}$ to pyrrolic $\mathrm{N}$ increased with prolonging the reaction time, which is reasonable since the CQDs can be continuously purified during the long hydrothermal process. Moreover, long reaction time could make more chlorine and nitrogen entered the crystal lattice of CQDs and influence on the carbonization of as-prepared CQDs at the same time, which is consistent with the Raman results. 

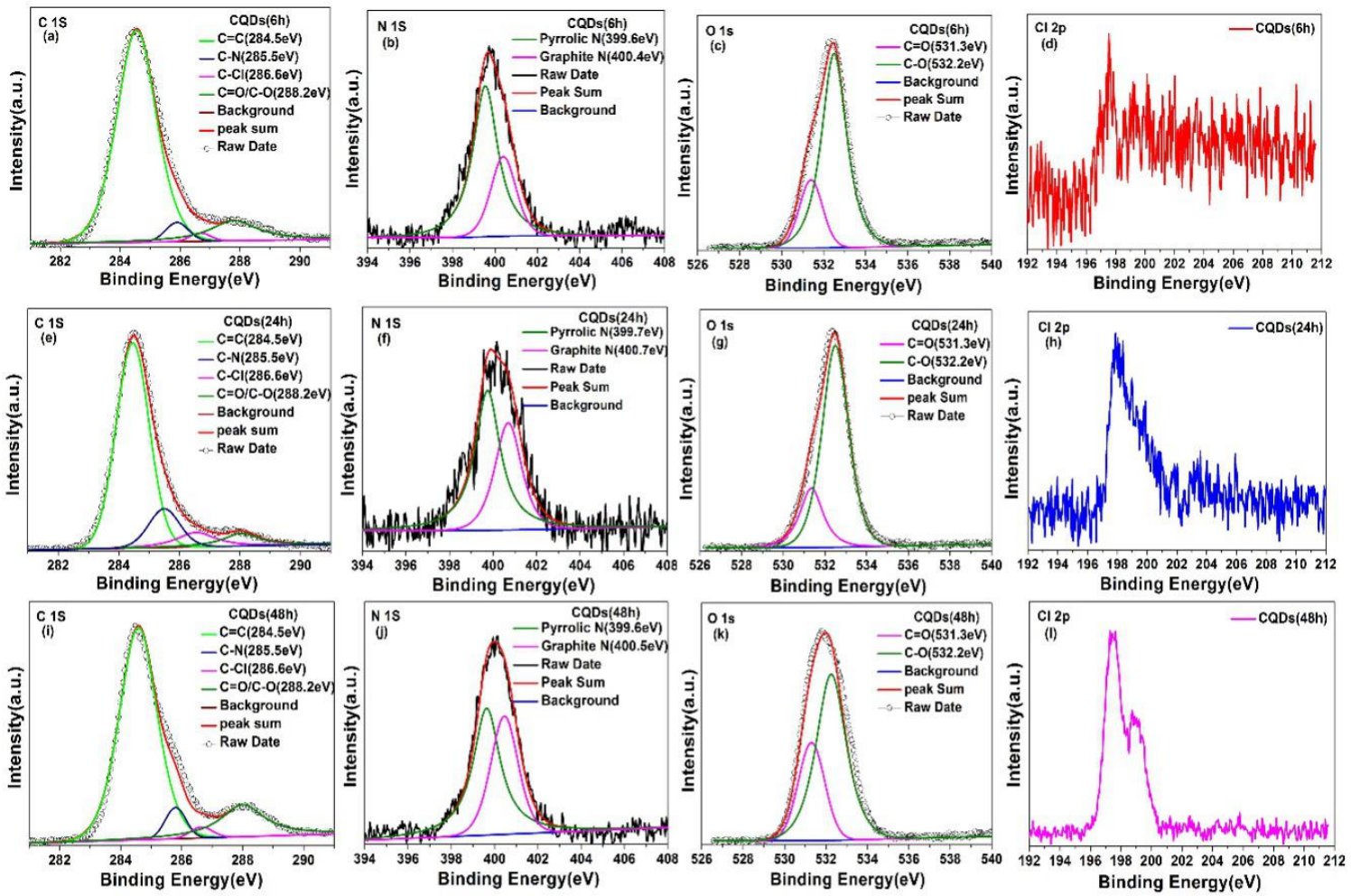

Figure 11. High-resolution $\mathrm{C}$ 1s, $\mathrm{N}$ 1s, $\mathrm{O}$ 1s and $\mathrm{Cl}$ 2p core level XPS spectra of CQDs (6 h) (a-d), CQDs (24 h) (e-h) and CQDs (48 h) (i-1).

Table 3. Intensity proportion of $\mathrm{C}-\mathrm{N}$ and $\mathrm{C}-\mathrm{Cl}$ in the $\mathrm{C} 1$ s spectra of CQDs (6 h), CQDs (24 h) and CQDs (48 h).

\begin{tabular}{cccc}
\hline Sample & CQDs (6 h) & CQDs (24 h) & CQDs (48 h) \\
\hline C-N & $4.13 \%$ & $4.46 \%$ & $5.40 \%$ \\
C-Cl & $1.57 \%$ & $1.94 \%$ & $2.16 \%$ \\
\hline
\end{tabular}

The FTIR spectra of CQDs $(6 \mathrm{~h})$, CQDs $(24 \mathrm{~h})$ and CQDs $(48 \mathrm{~h})$ are shown in Figure 12. The characteristic absorption peak at $1640 \mathrm{~cm}^{-1}, 1400 \mathrm{~cm}^{-1}, 600-800 \mathrm{~cm}^{-1}$ and $3000-3600 \mathrm{~cm}^{-1}$ are attributed to stretching vibrations of $\mathrm{C}=\mathrm{C}, \mathrm{C}-\mathrm{N}, \mathrm{C}-\mathrm{Cl}, \mathrm{C}-\mathrm{OH}$ and $\mathrm{N}-\mathrm{H}$ bond $[19,106]$, respectively. With prolonging the reaction time, the intensities of peaks related to $\mathrm{N}$ and $\mathrm{Cl}$ exhibit enhancement, indicating more $\mathrm{N}$ and $\mathrm{Cl}$ incorporates into the CQDs, at the same time, the carbon core is a purification process, so the $\mathrm{C}=\mathrm{C}$ bond has a slight increase in the FTIR spectra, which has a good agreement with the above Raman and XPS results. It is noteworthy that the signal of $\mathrm{C}=\mathrm{O}$ bond almost disappeared, which did not contribute to the luminescence process of CQDs.

Figure 13a shows the absorption spectra of CQDs (12 h), CQDs (24 h), CQDs (36 h) and CQDs ( $48 \mathrm{~h}$ ). Two characteristic peaks at $\sim 225 \mathrm{~nm}, \sim 260 \mathrm{~nm}$ and $\sim 292 \mathrm{~nm}$ can be ascribed to the $\pi-\pi^{*}$ transition of $\mathrm{C}=\mathrm{C}, \mathrm{C}=\mathrm{N}$ bond and $\mathrm{Cl}$-related state between $\pi$ valence band and $\pi^{*}$ conduction band $[63,69]$ respectively. Similar to Figure 7a, no absorption peak of $\mathrm{C}=\mathrm{O}$ was obtained, which is consistent to the results of Figure 12. The peak intensity of CQDs (12 h) at $225 \mathrm{~nm}$ is pretty weak, which was mainly caused by the incomplete formation of carbon core due to the short reaction time. With prolonging the reaction time to $36 \mathrm{~h}$, the peak intensity of $\sim 225 \mathrm{~nm}$ gradually enhanced, indicating the amount of $\pi$-domain increase step by step. However, when the reaction time is prolonged to $48 \mathrm{~h}$, the peak intensity of $\sim 225 \mathrm{~nm}$ starts to decrease due to more nitrogen or chlorine entering into the $\pi$-conjugated area. The intensity of peak located at $\sim 260 \mathrm{~nm}$ and $\sim 292 \mathrm{~nm}$ enhanced slightly during prolonging the reaction time to 48 hours, indicating that more $\mathrm{N}, \mathrm{Cl}-$ related states existed in CQDs ( $48 \mathrm{~h}$ ). 


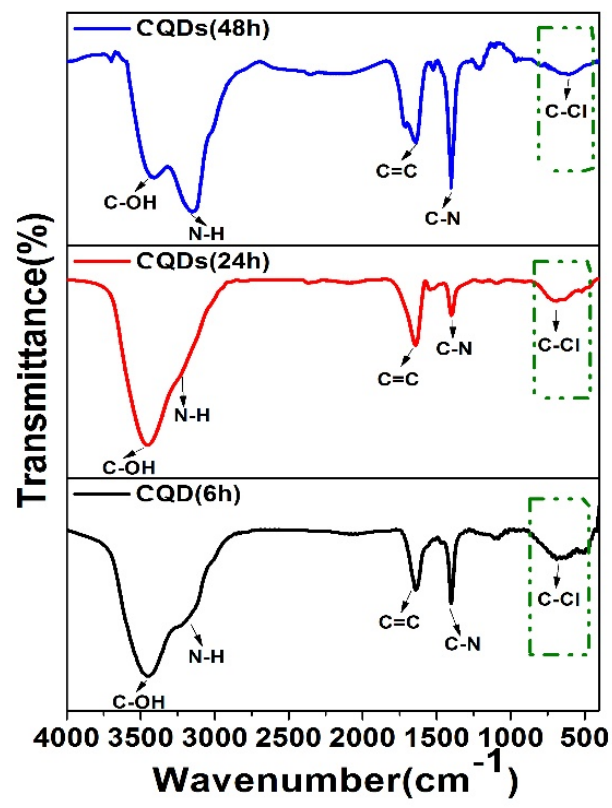

Figure 12. FTIR spectra of CQDs (6 h), CQDs (24 h) and CQDs (48 h).
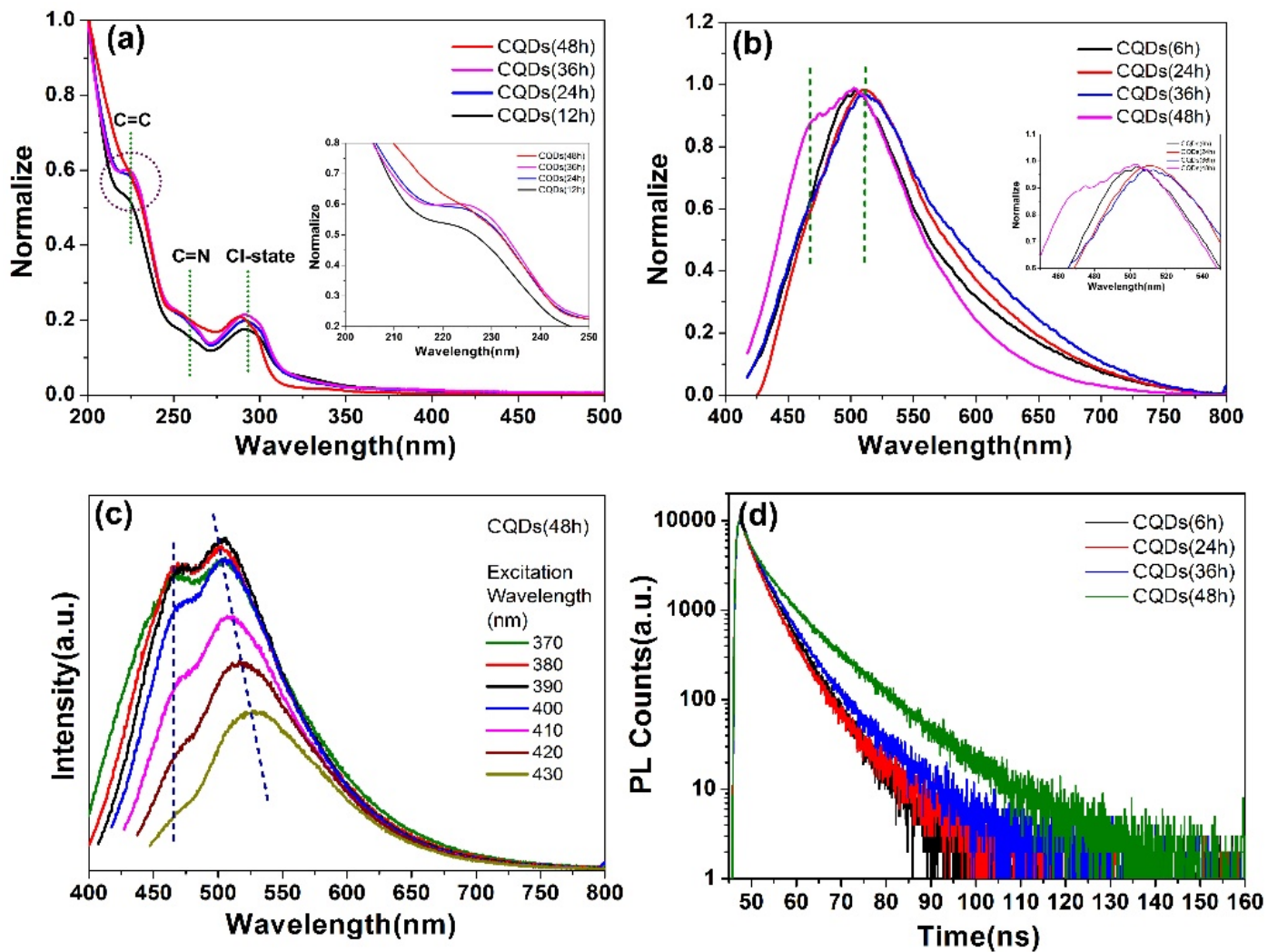

Figure 13. (a) UV-Vis absorption spectra of CQDs (12 h), CQDs (24 h), CQDs (36 h) and CQDs (48 h) in aqueous solutions (The inset is an enlarged view of absorbed by $\mathrm{C}=\mathrm{C})$; (b) PL spectra of CQDs (6 h), CQDs (24 h), CQDs (36 h) and CQDs (48 h) in aqueous solutions (The inset is an enlarged view of emission area in the range of $450 \mathrm{~nm}-550 \mathrm{~nm}$ ); (c) PL spectra of CQDs (48 h) excited at wavelength of 370-430 nm, with increments of $10 \mathrm{~nm}$; (d) PL decay curves of CQDs under excitation wavelength of $400 \mathrm{~nm}$. 
Figure $13 \mathrm{~b}$ shows the PL spectra of CQDs $(6 \mathrm{~h})$, CQDs $(24 \mathrm{~h}), \mathrm{CQDs}(36 \mathrm{~h})$ and CQDs (48 h). As shown in Figure 11b, the main luminescence center related to Cl-states of CQDs (6 h), CQDs (24 h), CQDs (36 h) and CQDs (48 h) located at $503 \mathrm{~nm}, 511 \mathrm{~nm}, 511 \mathrm{~nm}$ and $502 \mathrm{~nm}$ under excitation of 400 ex, respectively. With prolonging the reaction time from $6 \mathrm{~h}$ to $36 \mathrm{~h}$, the emission peak position exhibits a slight red-shift due to more $\mathrm{Cl}$ incorporating into CQDs [91]. A blue-shift can then be observed when reacting for $48 \mathrm{~h}$. As revealed by TEM results, the size of CQDs ( $48 \mathrm{~h})(1.5 \mathrm{~nm})$ is smaller than that of CQDs $(24 \mathrm{~h})(2.4 \mathrm{~nm})$. Such-blue shift can be assigned to the quantum confinement effects. Moreover, the shoulder emission peak at $466 \mathrm{~nm}$ derived from the conjugated $\pi$-domain obviously appeared after the reaction time reached to $48 \mathrm{~h}[107,108]$. It is well known that the reacting duration is a purification process for the CQDs. The degree of carbonization in CQDs (48 $\mathrm{h}$ ) is better than CQDs (6-36 h) proved by the above Raman results, which is beneficial for the appearance of shoulder peak at $466 \mathrm{~nm}$. Figure 13c displays the PL spectra of CQDs (48 h) at different excitation wavelength. A slight excitation dependent emission with the maximum emission at $512 \mathrm{~nm}$ due to the oxygen-containing groups on the surface of CQDs such as $\mathrm{C}-\mathrm{OH}, \mathrm{C}=\mathrm{O}$ and $\mathrm{COOH}$ and independent emission at $466 \mathrm{~nm}$ attributed to the good crystallization quality of CQDs confirmed by TEM and Raman results, which is similar to Figure 7b. The TRPL spectra of CQDs (6 h), CQDs (24 h), CQDs (36 h) and CQDs (48 h) are shown in Figure 13d. The derived lifetimes of $\tau_{1}$ and $\tau_{2}$ by double-exponential function fitting have been summarized in Table 4, which is analogous to other reported values [106]. As similar as Figure 7d, the longer lifetime of CQDs could attribute to the chlorine-related states and the shorter lifetime corresponded to the conjugated $\pi$-domains (intrinsic state). The extended average lifetime was attributed to the purification of carbon core and amount of nitrogen/chlorine in CQDs. The longer lifetime exhibited an increasing trend since more chlorine was introduced into the CQDs.

Table 4. The lifetime components of CQDs (12 h), CQDs (24 h), CQDs (36 h) and CQDs (48 h).

\begin{tabular}{ccccc}
\hline Sample & $\tau_{\mathbf{1}}$ (ns) & $\tau_{\mathbf{2}}$ (ns) & $\tau_{\text {average }}(\mathbf{n s})$ & $\chi^{\mathbf{2}}$ \\
\hline CQDs (6 h) & 2.31 & 5.29 & 3.57 & 1.54 \\
CQDs (24 h) & 2.46 & 6.11 & 3.32 & 1.05 \\
CQDs (36 h) & 2.90 & 7.11 & 3.94 & 0.78 \\
CQDs (48 h) & 2.50 & 9.47 & 4.62 & 0.68 \\
\hline
\end{tabular}

In order to further explore the fluorescence properties of the as-prepared CQDs, the quantum yield (QY) of the CQDs was investigated. The QY of the CQDs (24 h) were investigated. The QY of CQDs $(24 \mathrm{~h})$ was calculated with the following equation:

$$
\mathrm{Q}=\mathrm{Q}_{\mathrm{R}} \frac{\mathrm{I}}{\mathrm{I}_{\mathrm{A}}} \frac{\mathrm{A}_{\mathrm{R}}}{\mathrm{A}} \frac{\mathrm{n}^{2}}{\mathrm{n}_{\mathrm{R}}{ }^{2}}
$$

where $\mathrm{Q}$ is the quantum yield, I is the measured integrated emission intensity, $\mathrm{n}$ is the refractive index and $\mathrm{A}$ is the optical density. The subscript $\mathrm{R}$ refers to the reference fluorophore of known quantum yield. Under the excitation of $380 \mathrm{~nm}$, the QY of the CQDs (24 h) was measured to be $10.12 \%$ using quinine sulfate in $0.1 \mathrm{M} \mathrm{H}_{2} \mathrm{SO}_{4}(\mathrm{QY}=0.54)$ as a reference.

At present, the PL mechanism of carbon quantum dots is still an open topic, which needs deeper exploration. In the typical PL mechanism, it can be divided into two major categories: one is intrinsic state related to conjugated $\pi$-domains in CQDs [92,109], the other is surface/defect/edge state related to the surface groups or defects [15]. Based on the above massive data analysis, a novel PL mechanism has been proposed. As shown in Figure 14, the emission in blue-green regions of as-prepared CQDs can attribute to direct recombination of excited electrons from the conjugated $\pi$-domain and $\mathrm{Cl}$-related state. The chlorine and nitrogen could introduce additional energy level between $C_{\pi}$ and $C_{\pi^{*}}$. Based on the Figure 6 , the electron transitions can happen from $\mathrm{HOMO}\left(\mathrm{C}_{\pi}\right)$ to LUMO $\left(\mathrm{Cl}_{\pi^{*}}\right)$, LUMO $\left(\mathrm{N}_{\pi^{*}}\right)$ and LUMO $\left(\mathrm{C}_{\pi^{*}}\right)$. Due to nonradiative processes such as vibration relaxation and so forth, the excited electrons located at $\mathrm{LUMO}\left(\mathrm{C}_{\pi^{*}}\right)$ level will relax to $\mathrm{LUMO}\left(\mathrm{Cl}_{\pi^{*}}\right)$ 
or LUMO $\left(\mathrm{N}_{\pi^{*}}\right)$, thus two emissions at $466 \mathrm{~nm}$ derived from the conjugated $\pi$-domain and $512 \mathrm{~nm}$ originated from chlorine-related states happens at the same time. With variation of nitrogen and chlorine doping concentration, these two emissions will be tuned. Thus, the synergy and competition mechanism of chlorine-states and conjugated $\pi$-domain play the key role in the luminescence process of nitrogen and chlorine co-doped CQDs.

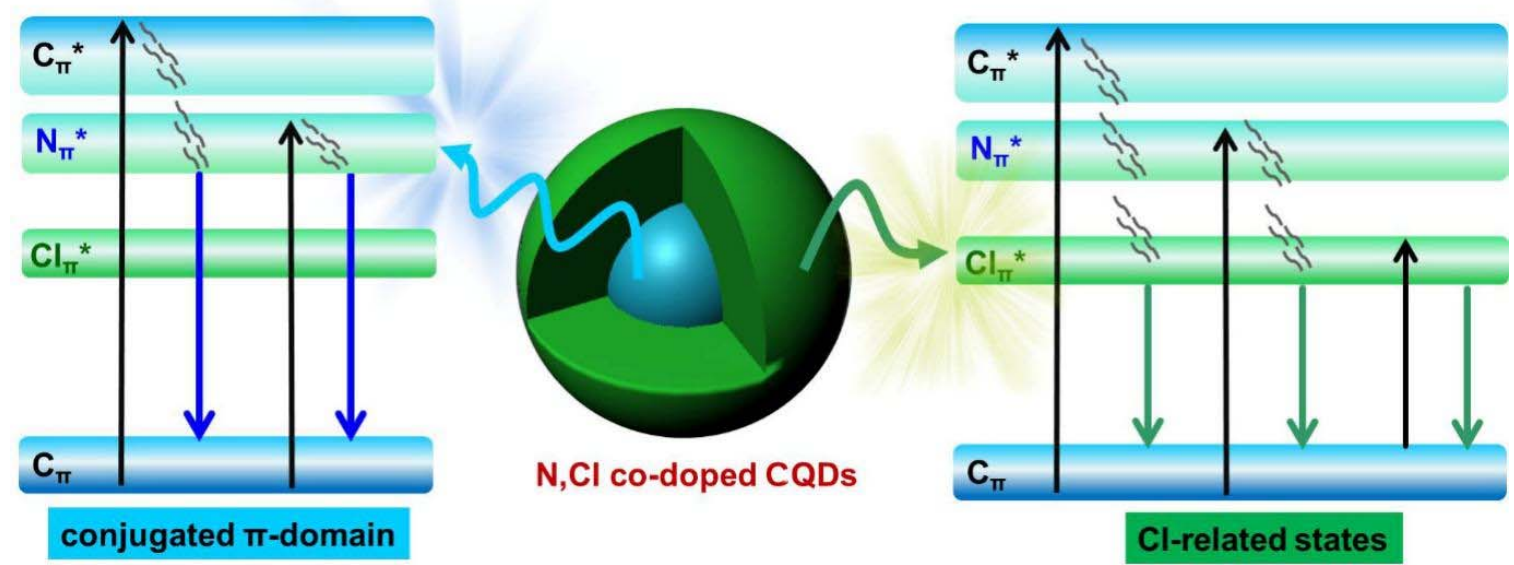

Figure 14. The speculated energy level diagram of the nitrogen and chlorine co-doped CQDs.

\section{Conclusions}

In summary, by nitrogen and chlorine co-doping, we successfully tune the emission wavelength of CQDs and further investigate co-doping effects on the luminescent properties of CQDs. We succeed to invent the ultra-small nitrogen and chlorine co-doped CQDs with unique blue-green double emissions by a facile hydrothermal method. The blue emission at $466 \mathrm{~nm}$ derived from the conjugated $\pi$-domain and green emission at $512 \mathrm{~nm}$ originated from chlorine-related states. It is revealed that chlorine and nitrogen introduced new energy levels between $C_{\pi}$ and $C_{\pi}{ }^{*}$ and the tunable blue-green double emissions of nitrogen and chlorine co-doped CQDs attribute to the synergy and competition mechanism of conjugated $\pi$-domain, quantum confinement effect and Cl-related state, which can be realized by controlling mole ratio of citric acid to BD and reaction time simply. The quantum yield of as-prepared CQDs is $10.12 \%$, which is lower than other traditional semiconductor quantum dots such as $\mathrm{CdSe}$ and $\mathrm{PbS}$ quantum dots but it is low in toxicity and super water-soluble, which is beneficial for bio-application. To enhance the luminescence quantum yield of CQDs, the works on removing the surface functional groups of CQDs, increasing the degree of carbonization of CQDs, or regulating the particle size and soon on are necessary to be carried out in the future.

Author Contributions: Conceptualization, H.L. and L.Y.; Writing-Original Draft Preparation, X.S.; Software, X.W.; Formal analysis, X.S., W.Y., J.C. and J.Y.; Investigation, X.S., M.W. and X.L.; Writing-Review \& Editing, H.L., L.Y. and S.G.X.

Funding: This research was funded by National Key Research and Development Program of China (Grant Nos. 2017YFF0108600, 2017YFF0108607), National Natural Science Foundation of China (Grant Nos. 61775081, $61475063,61705079,61605059,61505067)$, Program for the development of Science and Technology of Jilin province (Item No. 20180519016JH, 20180520182JH, 20180414008GH).

Conflicts of Interest: The authors declare no conflict of interest. 


\section{References}

1. Svedendahl, M.; Verre, R.; Kall, M. Refractometric Biosensing Based on Optical Phase Flips in Sparse and Short-Range-Ordered Nanoplasmonic Layers. Light Sci. Appl. 2014, 3, e220. [CrossRef]

2. Zhu, Z.; Bai, B.; You, O.; Li, Q.; Fan, S. Fano resonance boosted cascaded optical field enhancement in a plasmonic nanoparticle-in-cavity nanoantenna array and its SERS application. Light Sci. Appl. 2015, 4, e296. [CrossRef]

3. Wang, P.; Wang, Y.; Tong, L. Graphene-doped polymer nanofibers for low-threshold nonlinear optical waveguiding. Light Sci. Appl. 2013, 2, e102. [CrossRef]

4. Li, X.; Xing, L.; Zheng, K.; Wei, P.; Du, L.; Shen, M.; Shi, X. Formation of gold nanostar-coated hollow mesoporous silica for tumor multimodality imaging and photothermal therapy. ACS Appl. Mater. Interfaces 2017, 9, 5817-5827. [CrossRef] [PubMed]

5. Aslam, U.; Chavez, S.; Linic, S. Controlling energy flow in multimetallic nanostructures for plasmonic catalysis. Nat. Nano 2017, 12, 1000-1005. [CrossRef] [PubMed]

6. Zhang, Q.; Wang, H. Facet-Dependent Catalytic Activities of Au Nanoparticles Enclosed by High-Index Facets. ACS Catal. 2014, 4, 4027-4033. [CrossRef]

7. Karabchevsky, A.; Mosayyebi, A.; Kavokin, A.V. Tuning the chemiluminescence of a luminol flow using plasmonic nanoparticles. Light Sci. Appl. 2016, 5, 1-7. [CrossRef]

8. Linnenbank, H.; Grynko, Y.; Forstner, J.; Linden, S. Second harmonic generation spectroscopy on hybrid plasmonic/dielectric nanoantennas. Light Sci. Appl. 2016, 5, e16013. [CrossRef]

9. Blum, O.; Shaked, N.T. Prediction of photothermal phase signatures from arbitrary plasmonic nanoparticles and experimental verification. Light Sci. Appl. 2015, 4, e322. [CrossRef]

10. Zhu, J.; Mei, S.; Yang, W.; Zhang, G.; Chen, Q.; Zhang, W.; Guo, R. Tunable emission of Cu (Mn)-doped ZnInS quantum dots via dopant interaction. J. Colloid Interface Sci. 2017, 506, 27-35. [CrossRef] [PubMed]

11. Chen, B.; Meng, Q.; Zhong, H.; Sun, J.; Cheng, L.; Peng, Y.; Yu, T.; Chen, M. Quantum efficiency and surface passivation effect of nanocrystalline $\mathrm{Y}_{2} \mathrm{O}_{3}: \mathrm{Eu}^{3+}$. J. Nanosci. Nanotechnol. 2008, 8, 1165-1169. [PubMed]

12. Chong, Y.; Ma, Y.; Shen, H.; Tu, X.; Zhou, X.; Xu, J.; Dai, J.; Fan, S.; Zhang, Z. The in vitro and in vivo toxicity of graphene quantum dots. Biomaterials 2014, 35, 5041-5048. [CrossRef] [PubMed]

13. Liu, Q.; Guo, B.; Rao, Z.; Zhang, B.; Gong, J.R. Strong two-photon-induced fluorescence from photostable, biocompatible nitrogen-doped graphene quantum dots for cellular and deep-tissue imaging. Nano Lett. 2013, 13, 2436-2441. [CrossRef] [PubMed]

14. Tan, X.; Li, Y.; Li, X.; Zhou, S.; Fan, L.; Yang, S. Electrochemical synthesis of small-sized red fluorescent graphene quantum dots as a bioimaging platform. Chem. Commun. 2015, 51, 2544-2546. [CrossRef] [PubMed]

15. Ding, C.; Zhu, A.; Tian, Y. Functional surface engineering of c-dots for fluorescent biosensing and in vivo bioimaging. Acc. Chem. Res. 2013, 47, 20-30. [CrossRef] [PubMed]

16. Suzuki, K.; Malfatti, L.; Takahashi, M.; Carboni, D.; Messina, F.; Tokudome, Y.; Takemoto, M.; Innocenzi, P. Design of carbon dots photoluminescence through organo-functional silane grafting for solid-state emitting devices. Sci. Rep. 2017, 7, 5469. [CrossRef] [PubMed]

17. Qu, D.; Zheng, M.; Du, P.; Zhou, Y.; Zhang, L.; Li, D.; Tan, H.; Zhao, Z.; Xie, Z.; Sun, Z. Highly luminescent s, $\mathrm{n}$ co-doped graphene quantum dots with broad visible absorption bands for visible light photocatalysts. Nanoscale 2013, 5, 12272-12277. [CrossRef] [PubMed]

18. Qu, D.; Zheng, M.; Li, J.; Xie, Z.; Sun, Z. Tailoring color emissions from n-doped graphene quantum dots for bioimaging applications. Light Sci. Appl. 2015, 4, e364. [CrossRef]

19. Wang, D.W.; Wu, K.H.; Gentle, I.R.; Lu, G.Q. Anodic chlorine/nitrogen co-doping of reduced graphene oxide films at room temperature. Carbon 2012, 50, 3333-3341. [CrossRef]

20. Wu, Y.; Lin, X.; Shen, X.; Sun, X.; Liu, X.; Wang, Z.; Kim, J. Exceptional dielectric properties of chlorine-doped graphene oxide/poly (vinylidene fluoride) nanocomposites. Carbon 2015, 89, 102-112. [CrossRef]

21. Yang, S.; Sun, J.; Li, X.; Zhou, W.; Wang, Z.; He, P.; Ding, G.Q.; Xie, X.M.; Kang, Z.H.; Jiang, M.H. Large-scale fabrication of heavy doped carbon quantum dots with tunable-photoluminescence and sensitive fluorescence detection. J. Mater. Chem. A 2014, 2, 8660-8667. [CrossRef]

22. Bourlinos, A.B.; Zbořil, R.; Petr, J.; Bakandritsos, A.; Krysmann, M.; Giannelis, E.P. Luminescent surface quaternized carbon dots. Chem. Mater. 2012, 24, 6-8. [CrossRef] 
23. Li, H.; He, X.; Kang, Z.; Huang, H.; Liu, Y.; Liu, J.; Lian, S.; Tsang, C.H.; Yang, X.; Lee, S.T. Water-soluble fluorescent carbon quantum dots and photocatalyst design. Angew. Chem. 2010, 122, 4532-4536. [CrossRef]

24. Hu, S.L.; Niu, K.Y.; Sun, J.; Yang, J.; Zhao, N.Q.; Du, X.W. One-step synthesis of fluorescent carbon nanoparticles by laser irradiation. J. Mater. Chem. 2009, 19, 484-488. [CrossRef]

25. Jin, S.H.; Kim, D.H.; Jun, G.H.; Hong, S.H.; Jeon, S. Tuning the photoluminescence of graphene quantum dots through the charge transfer effect of functional groups. ACS Nano 2013, 7, 1239-1245. [CrossRef] [PubMed]

26. Chen, W.F.; Lv, G.; Hu, W.M.; Li, D.J.; Chen, S.N.; Dai, Z.X. Synthesis and applications of graphene quantum dots: A review. Nanotechnol. Rev. 2018, 7, 157-185. [CrossRef]

27. Iannazzo, D.; Ziccarelli, I.; Pistone, A. Graphene quantum dots: Multifunctional nanoplatforms for anticancer therapy. J. Mater. Chem. B 2017, 5, 6471-6489. [CrossRef]

28. Li, X.; Shu, P.L.; Tang, L.; Ji, R.; Yang, P. Multicolour light emission from chlorine-doped graphene quantum dots. J. Mater. Chem. C 2013, 1, 7308-7313. [CrossRef]

29. Zhao, J.; Tang, L.; Xiang, J.; Ji, R.; Yuan, J.; Zhao, J.; Yu, R.Y.; Tai, Y.J.; Song, L.Y. Chlorine doped graphene quantum dots: Preparation, properties, and photovoltaic detectors. Appl. Phys. Lett. 2014, 105, 8869. [CrossRef]

30. Xing, G.Z.; Wang, Y.; Wong, J.I.; Shi, Y.M.; Huang, Z.X.; Li, S.; Yang, H.Y. Hybrid $\mathrm{CuO} / \mathrm{SnO}_{2}$ nanocomposites: Towards cost-effective and high performance binder free lithium ion batteries anode materials. Appl. Phys. Lett. 2014, 105, 143905. [CrossRef]

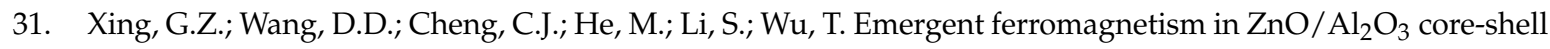
nanowires: Towards oxide spinterfaces. Appl. Phys. Lett. 2013, 103, 022402. [CrossRef]

32. Sun, Y.; Li, Q. Research of zinc oxide quantum dot light-emitting diodes based on preparation of chemical solutions. Chin. J. Liq. Cryst. Disp. 2016, 31, 635-642. [CrossRef]

33. Chen, X.Y.; Tian, Z. Recent progress in terahertz dynamic modulation based on graphene. Chin. Opt. 2017, 10, 86-97. [CrossRef]

34. Tong, L.; Mei-ling, Z.; Fei, W.; Da-ming, Z.; Guo-ping, W. Fabrication of optical waveguide amplifiers based on bonding-type NaYF4: Er nanoparticles-polymer. Chin. Opt. 2017, 10, 219-225. [CrossRef]

35. Huang, J.M.; Chen, E.G.; Guo, T.L. White-balance characteristic of quantum-dot backlight. Chin. J. Liq. Cryst. Disp. 2017, 32, 77. [CrossRef]

36. Sun, J.H.; Sui, H.D.; Wang, Z.W.; Wang, K.; Yan, Y.; Qi, L.U.; Ling, L. Preparation of europium-doped nano- $\mathrm{TiO}_{2}$ transparent photocatalyst emulsion and photocatalytic performance. Chin. Opt. 2017, 10, 761-767.

37. Qi, Y.L.; Wang, D.; Qiu, Y.; Shi, G.D. Ultro-high color gamut and patterned color filter based on quantum dot photoresist. Chin. J. Liq. Cryst. Disp. 2017, 32, 169.

38. Du, J.L.; Gao, B.R.; Wang, H.Y.; Chen, Q.D. Dynamics of low-threshold random laser based on TiO2 nanoparticle films. Chin. Opt. 2016, 9, 249-254. [CrossRef]

39. Wu, J.; Wang, H.; Su, Z.; Zhang, M.; Hu, X.; Wang, Y.; Wang, Z.; Zhong, B.; Zhou, W.; Liu, J.; et al. Highly flexible and sensitive wearable e-skin based on graphite nanoplatelet and polyurethane nanocomposite films in mass industry production available. ACS Appl. Mater. Interfaces 2017, 9, 38745-38754. [CrossRef] [PubMed]

40. Hong-Lei, J.I.; Zhou, Q.C.; Pan, J.; Bai, Z.L.; Zhong, H.Z. Advances and prospects in quantum dots based backlights. Chin. Opt. 2017, 10, 666-680. [CrossRef]

41. Zhang, F.; Xue, J.S.; Yu, Z.N.; Zhou, W.F.; Hui, G.B. Quantum-dot light emitting device for displays. Chin. J. Liq. Cryst. Disp. 2012, 27, 163-167. [CrossRef]

42. Qu, D.; Zheng, M.; Zhang, L.; Zhao, H.; Xie, Z.; Jing, X.; Haddad, R.E.; Fan, H.; Sun, Z. Formation mechanism and optimization of highly luminescent $\mathrm{N}$-doped graphene quantum dots. Sci. Rep. 2014, 4, 5294. [CrossRef] [PubMed]

43. Zhang, M.; Xia, P.; Wang, L.; Zheng, J.; Wang, Y.; Xu, J.; Wang, L. Synthesis and fabrication of CNTs/Fe3O4@Pdop@Au nanocables by a facile approach. RSC Adv. 2014, 4, 44423-44426. [CrossRef]

44. Matioli, E.; Brinkley, S.; Kelchner, K.M.; Hu, Y.L.; Nakamura, S.; DenBaars, S.; Speck, J.; Weisbuch, C. High-brightness polarized light-emitting diodes. Light Sci. Appl. 2012, 1, 479-482. [CrossRef]

45. Mitra, S.; Chandra, S.; Pathan, S.H.; Sikdar, N.; Pramanik, P. Room temperature and solvothermal green synthesis of self passivated carbon quantum dots. RSC Adv. 2013, 3, 3189-3193. [CrossRef]

46. Li, L.; Guo, W.; Yan, Y.; Lee, S.; Wang, T. Label-free super-resolution imaging of adenoviruses by submerged microsphere optical nanoscopy. Light Sci. Appl. 2013, 2, e104. [CrossRef] 
47. Shen, J.; Zhu, Y.; Chen, C.; Yang, X.; Li, C. Facile preparation and upconversion luminescence of graphene quantum dots. Chem. Commun. 2011, 47, 2580-2582. [CrossRef] [PubMed]

48. Xing, G.; Wang, D.; Yi, J.; Yang, L.; Gao, M.; He, M.; Yang, J.; Ding, J.; Sum, T.C.; Wu, T. Correlated d0 ferromagnetism and photoluminescence in undoped $\mathrm{ZnO}$ nanowires. Appl. Phys. Lett. 2010, 96, 112511. [CrossRef]

49. Cheng, X.; Zhang, J.; Ding, T.; Wei, Z.; Li, H.; Wang, Z. The effect of an electric field on the thermomechanical damage of nodular defects in dielectric multilayer coatings irradiated by nanosecond laser pulses. Light Sci. Appl. 2013, 2, e80. [CrossRef]

50. Wang, D.D.; Xing, G.Z.; Yan, F.; Yan, Y.S.; Li, S. Ferromagnetic (Mn, N)-codoped ZnO nanopillars array: Experimental and computational insights. Appl. Phys. Lett. 2014, 104, 022412. [CrossRef]

51. Pincella, F.; Isozaki, K.; Miki, K. A visible light-driven plasmonic photocatalyst. Light Sci. Appl. 2014, 3, 110-118. [CrossRef]

52. Xing, G.Z.; Fang, X.S.; Zhang, Z.; Wang, D.D.; Huang, X.; Guo, J.; Liao, L.; Zheng, Z.; Xu, H.R.; Yu, T. Ultrathin single-crystal $\mathrm{ZnO}$ nanobelts: Ag-catalyzed growth and field emission property. Nanotechnology 2010, 21, 255701. [CrossRef] [PubMed]

53. Wang, B.; Qu, S. Absorption spectra and near-electric field enhancement effects of Au- and Ag-Fe3O4 dimers. Appl. Surf. Sci. 2014, 292, 1002-1008. [CrossRef]

54. Zhang, X.; Song, L.; Cai, L.; Tian, X.; Zhang, Q.; Qi, X.; Zhou, W.; Zhang, N.; Yang, F.; Fan, Q.; et al. Optical visualization and polarized light absorption of the single-wall carbon nanotube to verify intrinsic thermal applications. Light Sci. Appl. 2015, 4, e318. [CrossRef]

55. Xing, G.Z.; Yi, J.B.; Wang, D.D.; Liao, L.; Yu, T.; Shen, Z.X.; Huan, C.H.A.; Sum, T.C.; Ding, J.; Wu, T. Strong correlation between ferromagnetism and oxygen deficiency in $\mathrm{Cr}$-doped $\operatorname{In}_{2} \mathrm{O}_{3-\delta}$ nanostructures. Phys. Rev. B 2009, 79, 174406. [CrossRef]

56. Xing, G.Z.; Yi, J.B.; Tao, J.G.; Liu, T.; Wong, L.M.; Zhang, Z.; Li, G.P.; Wang, S.J.; Ding, J.; Sum, T.C.; et al. Comparative study of room-temperature ferromagnetism in $\mathrm{Cu}$-doped $\mathrm{ZnO}$ nanowires enhanced by structural inhomogeneity. Adv. Mater. 2008, 20, 3521-3527. [CrossRef]

57. Wu, Z.L.; Zhang, P.; Gao, M.X.; Liu, C.F.; Wang, W.; Leng, F.; Huang, C.Z. One-pot hydrothermal synthesis of highly luminescent nitrogen-doped amphoteric carbon dots for bioimaging from bombyx mori silk-natural proteins. J. Mater. Chem. B 2013, 1, 2868-2873. [CrossRef]

58. Guo, L.; Ge, J.; Liu, W.; Niu, G.; Jia, Q.; Wang, H.; Wang, P. Tunable multicolor carbon dots prepared from well-defined polythiophene derivatives and their emission mechanism. Nanoscale 2015, 8, 729-734. [CrossRef] [PubMed]

59. Cayuela, A.; Soriano, M.L.; Carrillo-Carri, C.; Valcárcel, M. Semiconductor and carbon-based fluorescent nanodots: The need for consistency. Chem. Commun. 2016, 47, 1311-1326. [CrossRef] [PubMed]

60. Qu, Q.; Zhu, A.; Shao, X.; Shi, G.; Tian, Y. Development of a carbon quantum dots-based fluorescent Cu2+ probe suitable for living cell imaging. Chem. Commun. 2012, 48, 5473-5475. [CrossRef] [PubMed]

61. Lin, L.; Rong, M.; Lu, S.; Song, X.; Zhong, Y.; Yan, J.; Wang, Y.; Chen, X. A facile synthesis of highly luminescent nitrogen-doped graphene quantum dots for the detection of 2,4,6-trinitrophenol in aqueous solution. Nanoscale 2015, 7, 1872-1878. [CrossRef] [PubMed]

62. Hu, C.F.; Liu, Y.L.; Yang, Y.H.; Cui, J.H.; Wang, Y.L.; Yang, L.F.; Rong, J.H. One-step preparation of nitrogen-doped graphene quantum dots from oxidized debris of graphene oxide. J. Mater. Chem. B 2012, 1, 39-42. [CrossRef]

63. Zhang, M.; Bai, L.; Shang, W.; Xie, W.; Ma, H.; Fu, Y.; Fang, D.C.; Sun, H.; Fan, L.Z.; Han, M.; et al. Facile synthesis of water-soluble, highly fluorescent graphene quantum dots as a robust biological label for stem cells. J. Mater. Chem. 2012, 22, 7461-7467. [CrossRef]

64. Gu, J.; Hu, M.J.; Guo, Q.Q.; Ding, Z.F.; Sun, X.L.; Yang, J. High-yield synthesis of graphene quantum dots with strong green photoluminescence. RSC Adv. 2014, 4, 50141-50144. [CrossRef]

65. Nakamizo, M.; Kammereck, R. Laser raman studies on carbons. Carbon 1973, 12, 259-267. [CrossRef]

66. Das, A.; Pisana, S.; Chakraborty, B.; Piscanec, S.; Saha, S.K.; Waghmare, U.V.; Novoselov, K.S.; Krishnamurthy, H.R.; Geim, A.K.; Ferrari, A.C.; et al. Monitoring dopants by raman scattering in an electrochemically top-gated graphene transistor. Nat. Nanotechnol. 2008, 3, 210-215. [CrossRef] [PubMed] 
67. Kim, J.Y.; Lee, W.H.; Suk, J.W.; Potts, J.R.; Chou, H.; Kholmanov, I.N.; Piner, R.D.; Lee, J.; Akinwande, D.; Ruoff, R.S. Chlorination of reduced graphene oxide enhances the dielectric constant of reduced graphene oxide/polymer composites. Adv. Mater. 2013, 25, 2308-2313. [CrossRef] [PubMed]

68. Hu, S.; Chang, Q.; Lin, K.; Yang, J. Tailoring surface charge distribution of carbon dots through heteroatoms for enhanced visible-light photocatalytic activity. Carbon 2016, 105, 484-489. [CrossRef]

69. Zhao, J.; Tang, L.; Xiang, J.; Ji, R.; Hu, Y.; Yuan, J.; Zhao, J.; Tai, Y.J.; Cai, Y.H. Fabrication and properties of a high-performance chlorine doped graphene quantum dot based photovoltaic detector. RSC Adv. 2015, 5, 29222-29229. [CrossRef]

70. Zhang, J.H.; Niu, A.; Li, J.; Fu, J.W.; Xu, Q. In vivo characterization of hair and skin derived carbon quantum dots with high quantum yield as long-term bioprobes in zebrafish. Sci. Rep. 2016, 6, 37860. [CrossRef] [PubMed]

71. Liu, Q.; Xu, S.; Niu, C.; Li, M.; He, D.; Lu, Z.; Ma, L. Distinguish cancer cells based on targeting turn-on fluorescence imaging by folate functionalized green emitting carbon dots. Biosens. Bioelectron. 2015, 64, 119-125. [CrossRef] [PubMed]

72. Dong, Y.; Pang, H.; Yang, H.B.; Guo, C.; Shao, J.; Chi, Y.; Li, C.M.; Yu, T. Carbon-Based Dots Co-doped with Nitrogen and Sulfur for High Quantum Yield and Excitation-Independent Emission. Angew. Chem. Int. Ed. Engl. 2013, 125, 7954-7958. [CrossRef]

73. Chen, Y.F.; Wu, Y.Y.; Weng, B.; Wang, B.; Li, C.M. Facile synthesis of nitrogen and sulfur co-doped carbon dots and application for Fe(III) ions detection and cell imaging. Sens. Actuators B Chem. 2016, 223, 689-696. [CrossRef]

74. Joseph, J.; Anappara, A.A. Microwave-assisted hydrothermal synthesis of UV-emitting carbon dots from tannic acid. New J. Chem. 2016, 40, 8110-8117. [CrossRef]

75. Zhang, R.; Chen, W. Nitrogen-doped carbon quantum dots: Facile synthesis and application as a "turn-off" fluorescent probe for detection of $\mathrm{Hg}^{2+}$ ions. Biosens Bioelectron. 2014, 55, 83-90. [CrossRef] [PubMed]

76. Qu, D.; Sun, Z.; Zheng, M.; Li, J.; Zhang, Y.; Zhang, G.; Zhao, H.F.; Liu, X.Y.; Xie, Z.G. Three colors emission from $\mathrm{S}, \mathrm{N}$ co-doped graphene quantum dots for visible light $\mathrm{H} 2$ production and bioimaging. Adv. Opt. Mater. 2015, 3, 360-367. [CrossRef]

77. Roushani, M.; Mavaei, M.; Rajabi, H.R. Graphene quantum dots as novel and green nano-materials for the visible-light-driven photocatalytic degradation of cationic dye. J. Mol. Catal. A Chem. 2015, 409, 102-109. [CrossRef]

78. Song, Y.; Zhu, C.; Song, J.; Li, H.; Du, D.; Lin, Y. Drug-Derived Bright and Color-Tunable N-doped Carbon Dots for Cell Imaging and Sensitive Detection of Fe3+ in Living Cells. ACS Appl. Mater. Interfaces 2017, 9, 7399-7405. [CrossRef] [PubMed]

79. Kang, Y.F.; Li, Y.H.; Fang, Y.W.; Xu, Y.; Wei, X.M.; Yin, X.B. Carbon Quantum Dots for Zebrafish Fluorescence Imaging. Sci. Rep. 2015, 5, 11835. [CrossRef] [PubMed]

80. Thakur, M.; Mewada, A.; Pandey, S.; Bhori, M.; Singh, K.; Sharon, M.; Sharon, M. Milk-derived multi-fluorescent graphene quantum dot-based cancer theranostic system. Mater. Sci. Eng. C 2016, 67, 468-477. [CrossRef] [PubMed]

81. Tang, L.; Ji, R.; Li, X.; Bai, G.; Liu, C.P.; Hao, J.; Lin, J.; Jiang, H.; Teng, K.S.; Yang, Z.; et al. Deep ultraviolet to near-infrared emission and photoresponse in layered n-doped graphene quantum dots. ACS Nano 2014, 8 , 6312-6320. [CrossRef] [PubMed]

82. Mirzapoor, A.; Ranjbar, B. Biophysical and electrochemical properties of self-assembled noncovalent swnt/dna hybrid and electroactive nanostructure. Phys. E 2017, 93, 208-215. [CrossRef]

83. Chen, Y.; Zheng, M.; Xiao, Y.; Dong, H.; Zhang, H.; Zhuang, J.; Hu, H.; Lei, B.; Liu, Y. A self-quenchingresistant carbon-dot powder with tunable solid-state fluorescence and construction of dual-fluorescence morphologies for white light-emission. Adv. Mater. 2016, 28, 312-318. [CrossRef] [PubMed]

84. Noor, U.A.; Martin, O.E.; Susann, S.; Asghar, M.; Lin, P.C.; Mikael, S.; Reza, Y.G. Tuning the emission energy of chemically doped graphene quantum dots. Nanomaterials 2016, 6, 198. [CrossRef] [PubMed]

85. Wang, Y.; Kalytchuk, S.; Zhang, Y.; Shi, H.; Kershaw, S.V.; Rogach, A.L. Thickness-Dependent Full-Color Emission Tunability in a Flexible Carbon Dot Ionogel. J. Phys. Chem. Lett. 2014, 5, 1412-1420. [CrossRef] [PubMed]

86. Hu, S.; Trinchi, A.; Atkin, P.; Cole, I. Tunable Photoluminescence across the Entire Visible Spectrum from Carbon Dots Excited by White Light. Angew. Chem. Int. Ed. Engl. 2015, 54, 2970-2974. [CrossRef] [PubMed] 
87. Shi, Q.Q.; Li, Y.H.; Xu, Y.; Wang, Y.; Yin, X.B.; He, X.W.; Zhang, Y.K. High-yield and high-solubility nitrogen-doped carbon dots: Formation, fluorescence mechanism and imaging application. RSC Adv. 2014, 4, 1563-1566. [CrossRef]

88. Liang, Q.; Ma, W.; Shi, Y.; Li, Z.; Yang, X.M. Easy synthesis of highly fluorescent carbon quantum dots from gelatin and their luminescent properties and applications. Carbon 2013, 60, 421-428. [CrossRef]

89. Hu, S.; Tian, R.; Wu, L.; Zhao, Q.; Yang, J.; Liu, J.; Cao, S. Chemical regulation of carbon quantum dots from synthesis to photocatalytic activity. Chem. Asian J. 2013, 8, 1035-1041. [CrossRef] [PubMed]

90. Wu, M.B.; Wang, Y.; Wu, W.T.; Hu, C.; Wang, X.N.; Zheng, J.T.; Li, Z.T. Preparation of functionalized water-soluble photoluminescent carbon quantum dots from petroleum coke. Carbon 2014, 78, 480-489. [CrossRef]

91. Bolton, O.; Lee, K.; Kim, H.J.; Lin, K.Y.; Kim, J. Activating efficient phosphorescence from purely organic materials by crystal design. Nat. Chem. 2011, 3, 205-210. [CrossRef] [PubMed]

92. Kim, S.; Hwang, S.W.; Kim, M.K.; Shin, D.Y.; Shin, D.H.; Kim, C.O.; Yang, S.B. Anomalous Behaviors of Visible Luminescence from Graphene Quantum Dots: Interplay between Size and Shape. ACS Nano 2012, 6, 8203-8208. [CrossRef] [PubMed]

93. Peng, J.; Gao, W.; Gupta, B.K.; Liu, Z.; Romero-Aburto, R.; Ge, L.; Song, L.; Alemany, L.B.; Zhan, X. Graphene quantum dots derived from carbon fibers. Nano Lett. 2012, 12, 844-849. [CrossRef] [PubMed]

94. Ritter, K.A.; Lyding, J.W. The influence of edge structure on the electronic properties of graphene quantum dots and nanoribbons. Nat. Mater. 2009, 8, 235-242. [CrossRef] [PubMed]

95. Li, Y.; Zhao, Y.; Cheng, H.; Hu, Y.; Shi, G.; Dai, L.; Qu, L. Nitrogen-doped graphene quantum dots with oxygen-rich functional groups. J. Am. Chem. Soc. 2012, 134, 15-18. [CrossRef] [PubMed]

96. Ding, H.; Wei, J.S.; Xiong, H.M. Nitrogen and sulfur co-doped carbon dots with strong blue luminescence. Nanoscale 2014, 6, 13817-13823. [CrossRef] [PubMed]

97. Li, X.; Lau, S.P.; Tang, L.; Ji, R.; Yang, P. Sulphur doping: A facile approach to tune the electronic structure and optical properties of graphene quantum dots. Nanoscale 2014, 6, 5323-5328. [CrossRef] [PubMed]

98. Tang, L.; Ji, R.; Cao, X.; Lin, J.; Jiang, H.; Li, X.; Teng, K.S.; Luk, C.M.; Zeng, S.; Hao, J.; et al. Deep Ultraviolet Photoluminescence of Water-Soluble Self-Passivated Graphene Quantum Dots. ACS Nano 2012, 6, 5102-5110. [CrossRef] [PubMed]

99. Zhu, S.; Song, Y.; Wang, J.; Wan, H.; Zhang, Y.; Ning, Y.; Yang, B. Photoluminescence mechanism in graphene quantum dots: Quantum confinement effect and surface/edge state. Nano Today 2016. [CrossRef]

100. Song, S.H.; Jang, M.H.; Jeong, J.M.; Yoon, H.; Cho, Y.H.; Jeong, W.I.; Kim, B.H. Jeon S. Primary hepatocyte imaging by multiphoton luminescent graphene quantum dots. Chem. Commun. 2015, 51, 8041-8043. [CrossRef] [PubMed]

101. Hu, Y.; Yang, J.; Jia, L.; Yu, J.S. Ethanol in aqueous hydrogen peroxide solution: Hydrothermal synthesis of highly photoluminescent carbon dots as multifunctional nanosensors. Carbon 2015, 93, 999-1007. [CrossRef]

102. Liu, Y.; Zhou, L.; Li, Y.; Deng, R.; Zhang, H. Highly fluorescent nitrogen-doped carbon dots with excellent thermal and photo stability applied as invisible ink for loading important information and anti-counterfeiting. Nanoscale 2016, 9, 491-496. [CrossRef] [PubMed]

103. Qian, Z.; Ma, J.; Shan, X.; Feng, H.; Shao, L.; Chen, J. Highly luminescent N-doped carbon quantum dots as an effective multifunctional fluorescence sensing platform. Chem. A Eur. J. 2014, 20, 2254-2263. [CrossRef] [PubMed]

104. Ding, H.; Yu, S.B.; Wei, J.S.; Xiong, H.M. Full-color light-emitting carbon dots with a surface-state-controlled luminescence mechanism. ACS Nano 2016, 10, 484-491. [CrossRef] [PubMed]

105. Sumpter, B.G.; Meunier, V.; Romoherrera, J.M.; Cruzsilva, E.; Cullen, D.A.; Terrones, H.; Smith, D.J.; Terrones, M. Nitrogen-mediated carbon nanotube growth: Diameter reduction, metallicity, bundle dispersability, and bamboo-like structure formation. ACS Nano 2007, 1, 369-375. [CrossRef] [PubMed]

106. Chandra, S.; Laha, D.; Pramanik, A.; Ray, A.C.; Karmakar, P.; Sahu, S.K. Synthesis of highly fluorescent nitrogen and phosphorus doped carbon dots for the detection of $\mathrm{Fe}(3+)$ ions in cancer cells. Luminescence 2016, 31, 81-87. [CrossRef] [PubMed]

107. Dong, Y.; Shao, J.; Chen, C.; Li, H.; Wang, R.; Chi, Y.; Lin, X.M.; Chen, G.N. Blue luminescent graphene quantum dots and graphene oxide prepared by tuning the carbonization degree of citric acid. Carbon 2012, 50, 4738-4743. [CrossRef] 
108. Zhao, P.H.; Luo, Y.; Kong, L.Y. One-step preparation of green fluorescent graphene quantum dots from petroleum asphalt. J. Nano Res. 2017, 45, 76-83. [CrossRef]

109. Liu, F.; Jang, M.H.; Ha, H.D.; Kim, J.H.; Cho, Y.H.; Seo, T.S. Facile synthetic method for pristine graphene quantum dots and graphene oxide quantum dots: Origin of blue and green luminescence. Adv. Mater. 2013, 25, 3657-3662. [CrossRef] [PubMed] 